\title{
Meeting Correlated Spare Part Demands with Optimal Transshipments
}

\author{
Nagihan Çömez, Bilkent University, Turkey \\ Kathryn E. Stecke, University of Texas at Dallas, USA \\ Metin Çakanyıldırım, University of Texas at Dallas, USA
}

\begin{abstract}
This paper studies spare part transshipments between two service part facilities whose demands are correlated. Transshipments are used to reduce severity of part stock outs. Facilities are run by an inventory manager (IM) who minimizes replenishment, transshipment, and inventory costs. We show that the optimal transshipment policy is an inventory hold-back type; if the part inventory at a facility is less than or equal to its hold-back level, a transshipment request made for that part by a stocked out retailer is rejected. The hold-back levels increase toward the next replenishment of partsThis implies that transshipment requests are initially accepted until a critical time and afterwards they are rejected. A heuristic is designed using this critical time as the single decision variable. It performs within 0.7-1.8\% of the optimal cost. Heuristic policies of no inventory sharing and complete sharing, respectively, perform within $3 \%$ and $2 \%$ of the optimal cost. Since the computation of hold-back levels and implementation of the optimal transshipments, respectively, require limited resources and little IM oversight, we advocate for the use of the optimal transshipment policy.
\end{abstract}

Keywords: $\quad$ Correlated Demands, Heuristics, Hold-Back, Optimal Transshipments, Sensitivity Studies

\section{INTRODUCTION}

In a highly competitive business environment, after-sales service quality is crucial to improve the overall experience of existing customers and to boost purchase intentions of new customers (Ranaweera \& Neely, 2003). An unexpected disruption to after-sales service can severely undercut the current demand (Zandi, 2008). Besides, service quality is important to guar-

DOI: $10.4018 /$ jsds.2010040101 antee the continuity of demand for the service operations, which constitute $40-80 \%$ of some manufacturers' profit (Wu \& Tew, 2005). After-sales service can be counter cyclical to original equipment sales. In the four month period starting with the U.S. Senate hearings on dropping automobile sales in December 2008, the stock prices of car part suppliers Autozone, Advanced Auto Parts, and O'Reilly Automotive have, respectively, increased by $60 \%, 46 \%$, and $52 \%$ while the same numbers have been $-7 \%$ and $-58 \%$ for Dow Jones Industrial and General 
Motors. This indicates a negative correlation between after-sales service demand and original equipment demand. Thus, the significance of after-sales service can increase even further in economic slumps.

Responsiveness of the service is an important dimension of service quality. In many studies, part availability is shown to be a significant determinant of response time and thus the determinant of service quality. Wu and Tew (2005) state that dealer stock outs for service parts lead to either increased costs due to emergency orders or unsatisfactory service for vehicle owners. Shahla (2006) mentions that usually "users perceive customer service as the availability of an item".

To improve part availability without increasing overall inventory levels, inventory sharing among service facilities is an effective strategy. In an inventory sharing system, a service facility that is stocked-out of a certain part and has a request waiting to be satisfied by using that part may receive the part from another facility. Inventory sharing is commonly practiced to increase part availability either for internal operational use or for after-sales repair services. Sharing of repair parts for construction equipment, aircraft, and power-generating plants are considered in Grahovac and Chakravarty (2001) and Kukreja, Schmidt, and Miller (2001). Flint (1995) estimates that the airline industry stores $\$ 45$ billion worth of spare parts and suggests that spare parts inventories can be reduced by developing supplier partnerships that include transshipments.

Inventory sharing in distribution systems, such as Volvo GM Heavy Truck and Okuma America, are flexible and responsive because they leverage opportunities and share capabilities (Narus \& Anderson, 1996). To concretely visualize and to continue with the earlier automobile example, companies such as Autozone, Advanced Auto Parts, and O'Reilly Automotive are among the application areas of inventory sharing. Finding company-issued reports on lack of inventory sharing is harder as such reports can indicate lack of customer service. However, customers publicly complain(Complaints.com,
$2002,2007 a, b, c)$ when the inventory is not shared to meet their demand.

The common features of a repair part often include significant replenishment times from manufacturers and fairly high profit margins. Another feature is low and infrequent demand for the part because of its specific functionality and/or high variety within its product family. Orders for low-demand products usually arrive in single-units and monthly demand is often in two digits, e.g., around 25 for a spare part (Zhao, Deshpande, \& Ryan, 2005). For these, a low level of inventory can be kept at each facility by relying on inventory sharing to handle stock-outs.

In this paper, we study a centralized system of two service facilities, which are replenished periodically by a manufacturer for a single part type. Between two replenishments, a stockedout facility (requesting facility) can request a part from another facility (requested facility). The requests are accepted/rejected by an Inventory Manager (IM) in charge of the centralized system. If the request is accepted, the requested facility sends the part to the requesting facility. The part takes a transshipment time to arrive at the requesting facility. If the request is rejected, satisfaction of customer service is delayed until the next replenishment. During both the transshipment time and waiting time until the next replenishment, backorder cost per unit time is charged. Taking both the transportation time and cost between locations into account, we strive for a realistic model of inventory sharing, called transshipment.

The time between two replenishments in a row is called the replenishment cycle. The IM decides on the order quantities at the beginning of the replenishment cycle and transshipments during the cycle to minimize the system cost including inventory holding, backorder, transshipment, and ordering costs. With this objective, we obtain an optimal transshipment policy that is specified by facility-specific dynamic hold-back levels, which are functions of the number of periods until the next replenishment from the manufacturer. These levels can be communicated to each facility at the beginning 
of the cycle to make the IM's oversight unnecessary during the cycle and hence to facilitate the implementation.

Here we study transshipments that are allowed after, hence depending on, demand realizations called lateral transshipments, first studied by Krishnan and Rao (1965). Significant amount of work in this area is devoted to centrally managed systems with the exception of some decentralized systems (Rudi, Kapur, \& Pyke, 2001; Anupindi, Bassok, \& Zemel, 2001; Zhao et al., 2005; Sošić, 2006; Çömez, Stecke, \& Çakanyıldırım, 2009b).

Previous studies mainly focus on replenishment policy while transshipments are often considered by preestablished rules. Herer and Rashit (1999) studies the effect of fixed and joint ordering costs. Tagaras and Cohen (1992) and Tagaras (1999) introduce non-zero replenishment lead times. In Axsäter (1990), Grahovac and Chakravarty (2001), and Kukreja et al. (2001), replenishment is made after each demand arrival called one-for-one replenishment. $\mathrm{Xu}$, Evers, and $\mathrm{Fu}$ (2003) analyze a two-location transshipment model using an $(R, Q)$ replenish-

ment policy under a customer service consideration.

Studies considering multiple transshipments in a replenishment cycle are scarce in the literature, except Archibald, Sassen, and Thomas (1997) and Çömez, Stecke, and Çakanyıldırım (2009a) in a centralized setting and Çömez et al. (2009b) in a decentralized setting. In Archibald et al. (1997), unsatisfied demands are satisfied through emergency orders from the manufacturer, so there is no backordering at the service facilities. Inventory holding cost is charged only at the end of a replenishment cycle but not throughout. The demands are independent Poisson processes. The optimal policy obtained in Archibald et al. (1997) can be shown to imply increasing ${ }^{1}$ hold-back levels with the time until the next replenishment. In contrary, Çömez et al. (2009a) show that optimal hold-back levels are decreasing in time when there is non-negligible transshipment time and continuously incurred holding and backorder costs. Namely, facilities in their setting are more likely to transship inventory at the beginning of a replenishment cycle than those in Archibald et al. (1997). Both policies are optimal for their respective settings. However, the situation is delicate; a practitioner must implement the policy appropriate for his/her setting to avoid doing the opposite of the optimal. We also study a setting similar to that in Çömez et al. (2009a) to study demand correlation and heuristic transshipment policies.

Although scarce, there are transshipment studies considering the dependencies between the demands of transshipping facilities. All of these studies investigate replenishment policies while assuming complete pooling (Herer, Tzur, \& Yücesan, 2006; Dong \& Rudi, 2004; Zhang, 2005). To the best of our knowledge, there is no study of demand dependencies with optimal transshipment policies. Zhao, Ryan, and Deshpande (2008) lists consideration of dependent demands as a future work.

This paper provides optimal and implementable transshipment and replenishment policies by incorporating more aspects of reality than previous studies. These aspects include holding costs incurred within a replenishment cycle, backordering costs, multiple transshipments within a replenishment cycle, positive transshipment times and costs, and dependent demands. Thus, we provide a realistic spare parts inventory sharing model that can help service facilities to increase their coordination and hence part availability without increasing investment in parts, which are reported among the top ten challenges faced by service part facilities (Boone, Craighead, \& Hanna, 2008).

\section{TRANSSHIPMENT AND REPLENISHMENT MODEL}

Before proposing a mathematical model, we discuss the ingredients and setting of the model.

Dependent demands: A demand model is a good starting point for studying spare parts availability. Spare part demands are known to be erratic and low (Grahovac \& Chakravarty, 2001; Kukreja et al., 2001). For a particular 
part, there may be extended periods of time with no demand. For example, demands for a spare part of Airbus A320 aircrafts employed by Alitalia are zero for several months (Regattieria, Gamberi, Gamberini, \& Manzini, 2005). This sort of demand sparsity can justify adopting a Poisson process for the demand at a single service facility.

Zhang (2007) states that "when few players compete in a market, their strategic interactions are likely to produce demands that are cross-correlated". To jointly study part availability at several service facilities, a joint demand distribution is needed, whose marginal distributions preferably yield Poisson demands. Failing to find such a demand model in the literature, we propose one. We develop a discrete time model by dividing a replenishment cycle into $N$ short decision periods as in Lee and Hersh(1993). By choosing $N$ arbitrarily large, the decision periods can be made short enough to accommodate at most one spare part demand at each facility. For two service facilities, let $p_{11}$ be the probability of demand at both facilities 1 and 2, and let $p_{00}$ be the probability of no demand at either facility. $p_{10}$ and $p_{01}$ are the probabilities of a spare part demand only at facility 1 and only at facility 2 , respectively, where $p_{00}+p_{01}+p_{10}+p_{11}=1$. The correlation of demands at these two facilities is

$$
\rho=\frac{p_{00} p_{11}-p_{01} p_{10}}{\sqrt{\left(p_{10}+p_{11}\right)\left(p_{01}+p_{00}\right)\left(p_{01}+p_{11}\right)\left(p_{10}+p_{00}\right)}},
$$

which signifies the versatility of the demand model by allowing negatively, positively correlated, or independent demands. Method of moments estimators can be used to fit the empirical demand data to this model. The details are presented in Appendix A.

Spare part demands at different facilities are positively correlated if these facilities are subject to the same demand drivers. For example,
Çakanyıldırım et al. (2008) note a heat wave as a cause of air conditioner failures and show it to be a major driver of air conditioner demand.

On the other hand, demands can be negatively correlated when a random market size is randomly split between two facilities. To illustrate, think of Camry flat tire replacements by two Toyota service facilities in a city: Northern Toyota is in the north and Southern Toyota is in the south. When there is a Camry with a flat tire, it can be towed to either Northern Toyota or Southern Toyota depending on which is closer and/or which/if a facility covers the replacement under a warranty, etc. Thus, there is a negative correlation between facility demands as a consequence of such a split of the total random tire demand. This example can be replicated for other car service parts such as batteries, brake pads/liquids, and windshields.

A special case of our demand distribution, $p_{11}=0$, yields a multinomial distribution, used as a demand distribution in different contexts by Lee and Tang (1998) and Righter and Shanthikumar (2001). Each of our marginal distributions converges to a Poisson distribution in the limiting case of $N \rightarrow \infty$ when $p_{11}=0$, and $N p_{01}$ and $N p_{10}$ are kept constant. Thus, our demand model generalizes the one in Archibald et al. (1997).

In this paper, we study the stocking of the same spare part at two facilities. We can also study stocking two spare parts at the same facility with the same model. We only need to interpret $p_{i j}$ as the probability of demand of $i$ for part 1 and demand of $j$ for part 2 for $i, j \in\{0,1\}$. This interpretation easily extends to the forthcoming parameters. In that case, a transshipment has to be thought as a spare part substitution, perhaps after a modification cost (analogous to a transshipment cost). This substitution is called cannibalization in Kennedy, Patterson, and Fredendall (2002), which puts forth justification of cannibalization as an important issue often faced by maintenance 
managers. Our model weighs the modification cost, holding/backorder costs, and future demands to mathematically justify spare part cannibalization.

Kennedy et al. (2002) also underline that "part failures are often dependent". For example, consider the fan of a heat sink in a computer. If the fan fails, the temperature rises inside the computer, which in turn damages the sensitive electronic equipment such as the processor. In this case, fan and processor failures are naturally dependent. This dependence leads to dependent demands for spare parts. To the best of our knowledge, there is no dependent demand model for spare parts in the literature.

Multiple transshipments per replenishment cycle: In practice, a facility that receives a customer demand may respond to the customer in several different ways, such as satisfying the demand immediately, promising to provide the item from another facility, or backordering until the next replenishment. However, whatever the response is, the facility should respond to the customer quickly. Therefore, we allow for a transshipment decision after each individual demand realization. Most transshipment studies, except for Archibald et al. (1997), allow a single transshipment either in the middle or at the end of a replenishment cycle. The problem with transshipment in the middle of the cycle is that facilities rarely run out of inventory before the middle of the cycle, so transshipments are often not needed. The problem with transshipment at the end of the cycle is problematic as well. In that case, a stocked out facility can order from the manufacturer instead of requesting transshipments from another facility. Restricting transshipments to the middle or the end of a cycle does not allow their use at their full potential. In practice, each customer request should be immediately responded to. The response can involve backordering whose cost should be captured properly. These are important ingredients of our model.

Post-stock-out transshipments: We have learned through our personal communications with car service facilities of several brands that transshipments happen generally after stock- outs and not before. Given that spare parts are generally high in variety and thus have low demand rates per type (Grahovac \& Chakravarty, 2001), transshipments before a stock-out have a high risk of remaining in inventory until the next replenishment. In view of our application of transshipments to slow moving service parts as an emergency source of demand supply, a transshipment before demand materialization is unlikely. Especially when transshipment costs are significant, receiving a transshipment before a stock-out would likely not benefit the system. Furthermore, when the transshipment lead time is short, the issue of transshipping before a demand realization is minor (Grahovac \& Chakravarty, 2001; Zhao et al., 2006).

Transshipment lot size of one: Service facilities usually get the regular replenishments by the supplier's own fleet and use 3PL for transshipments. The reasons are that transshipment quantity is much less than replenishment quantity and that transshipment times are not predetermined unlike replenishment times. In our model, inventories are transshipped in single units. This follows from practice, where the economies of scale provided by third party carriers are generally not large enough to compensate for the expected additional backorder cost of delaying transshipments to consolidate them into a single shipment. Note that the previous studies consider no economies of scale in transshipment cost (Archibald et al., 1997; Zhao et al., 2005, 2006). To avoid delays due to consolidation, a facility can perhaps transship in expectation of the stocked-out demand before it happens. But this violates post-stock-out transshipments explained above.

\subsection{System Cost}

The replenishment problem is modeled over a horizon of infinitely many replenishment cycles. Within a cycle, $V_{n}\left(x_{1}, x_{2}\right)$ stands for the minimum expected total cost in the remaining $n$ periods until the next spare part replenishment if the current inventory levels are $x_{1}$ and $x_{2}$ at facilities 1 and 2 . The optimal centralized cost 
$V_{n}\left(x_{1}, x_{2}\right)$ is recursively obtained in three

cases: (i) when both facilities have stock; (ii) when both are stocked-out; (iii) when one is stocked-out, while the other still has stock.

Let $\mathcal{N}=\{1,2, \ldots\}$ be the set of natural numbers and $\mathcal{N}^{-}=\{0,-1,-2, \ldots\}$ be the set of nonpositive integers. In period $n$, if the current inventory levels of both facilities are positive, each facility satisfies his own demand if it exists. $V_{n}\left(x_{1}, x_{2}\right)$ is calculated by conditioning on the demand arrivals at facilities.

$$
\begin{gathered}
V_{n}\left(x_{1}, x_{2}\right) \\
=p_{00}\left[V_{n-1}\left(x_{1}, x_{2}\right)+h_{1} x_{1}+h_{2} x_{2}\right] \\
+p_{11}\left[V_{n-1}\left(x_{1}-1, x_{2}-1\right)+h_{1}\left(x_{1}-1\right)+h_{2}\left(x_{2}-1\right)\right] \\
+p_{10}\left[V_{n-1}\left(x_{1}-1, x_{2}\right)+h_{1}\left(x_{1}-1\right)+h_{2} x_{2}\right] \\
+p_{01}\left[V_{n-1}\left(x_{1}, x_{2}-1\right)+h_{1} x_{1}+h_{2}\left(x_{2}-1\right)\right] \\
x_{1}, x_{2} \in \mathcal{N},
\end{gathered}
$$

where $h_{i}$ is the holding cost at facility $i$. If both facilities are stocked out, any demand arrived is backordered and a backorder cost until the next replenishment is incurred.

$$
\begin{aligned}
& V_{n}\left(x_{1}, x_{2}\right)=p_{00}\left[V_{n-1}\left(x_{1}, x_{2}\right)\right] \\
& +p_{11}\left[2 n \pi+V_{n-1}\left(x_{1}-1, x_{2}-1\right)\right] \\
& \quad+p_{10}\left[n \pi+V_{n-1}\left(x_{1}-1, x_{2}\right)\right] \\
& +p_{01}\left[n \pi+V_{n-1}\left(x_{1}, x_{2}-1\right)\right], x_{1}, x_{2} \in \mathcal{N}^{-},
\end{aligned}
$$

where $\pi$ is the backorder cost.

In a replenishment cycle, suppose that facility 2 stocks-out before facility 1 . Each time facility 2 needs the part, a request is sent to facility 1 . The request is accepted if this results in lower system cost for the remainder of the replenishment cycle; otherwise it is rejected. This tradeoff is captured by minima below.

$$
\begin{aligned}
& \quad V_{n}\left(x_{1}, x_{2}\right) \\
& \quad=p_{00}\left[V_{n-1}\left(x_{1}, x_{2}\right)+h_{1} x_{1}\right] \\
& +p_{10}\left[V_{n-1}\left(x_{1}-1, x_{2}\right)+h_{1}\left(x_{1}-1\right)\right] \\
& \quad+p_{01}\left[\operatorname { m i n } \left\{K+V_{n-1}\left(x_{1}-1, x_{2}\right)\right.\right. \\
& \left.\left.\left.+h_{1}\left(x_{1}-1\right), n \pi+V_{n-1}\left(x_{1}, x_{2}-1\right)\right\}+h_{1} x_{1}\right\}\right] \\
& \quad+p_{11}\left[\operatorname { m i n } \left\{K+V_{n-1}\left(x_{1}-2, x_{2}\right)\right.\right. \\
& \left.\left.+h_{1}\left(x_{1}-2\right), n \pi+V_{n-1}\left(x_{1}-1, x_{2}-1\right)+h_{1}\left(x_{1}-1\right)\right\}\right] \\
& x_{1} \geq 2, x_{2} \in \mathcal{N}^{-},
\end{aligned}
$$

where $K$ is the transshipment cost. $K$ can include transportation cost as well as holding and backorder costs during a transshipment, which takes a positive amount of time.

A facility meets her own demand before entertaining transshipment requests.

$$
\begin{aligned}
& V_{n}\left(1, x_{2}\right)=p_{00}\left[V_{n-1}\left(1, x_{2}\right)+h_{1}\right] \\
& +p_{10} V_{n-1}\left(0, x_{2}\right)+p_{11}\left[V_{n-1}\left(0, x_{2}-1\right)+n \pi\right] \\
& +p_{01}\left[\operatorname { m i n } \left\{K+V_{n-1}\left(0, x_{2}\right), n \pi\right.\right. \\
& \left.\left.\left.+V_{n-1}\left(1, x_{2}-1\right)\right\}+h_{1}\right\}\right], x_{2} \in \mathcal{N}^{-} .
\end{aligned}
$$

At the end of a cycle, right before a replenishment arrival,

$$
V_{0}\left(x_{1}, x_{2}\right)=0
$$

Since the facilities are arbitrarily numbered, we do not explicitly consider cases obtained by replacing $x_{1}$ with $x_{2}$ such that $\left[x_{1} \in \mathcal{N}^{-}, x_{2}=1\right]$, which is analogous to (5).

During a replenishment cycle, facilities 1 and 2 face binomial demands denoted by random variables $\operatorname{Bin}\left(N, p_{10}+p_{11}\right)$ and $\operatorname{Bin}\left(N, p_{01}+p_{11}\right)$. Facility inventories are replenished based on the demands $\xi_{1}$ and $\xi_{2}$ handled by facilities 1 and 2. If no facility stocks out, demands $\xi_{1}$ and $\xi_{2}$ are $\operatorname{Bin}\left(N, p_{10}+p_{11}\right)$ 
and $\operatorname{Bin}\left(N, p_{01}+p_{11}\right)$. On the other hand, a facility that transships to a stocked-out facility handles more demand than the binomial demand she faces from her own customers. In particular, if facility 2 stocks out and facility 1 transships $k$ parts, $\xi_{1}=\operatorname{Bin}\left(N, p_{10}+p_{11}\right)+k$ and $\xi_{2}=\operatorname{Bin}\left(N, p_{01}+p_{11}\right)-k$. To highlight the dependence of $\xi_{i}$ on the inventory levels $\left(z_{1}, z_{2}\right)$ at the start of a replenishment cycle, its denoted by $\xi_{i}\left(z_{1}, z_{2}\right)$. Since the total demand met by the facilities is equal to the total demand arriving into the system, we have $\xi_{1}\left(z_{1}, z_{2}\right)+\xi_{2}\left(z_{1}, z_{2}\right)$

$=\operatorname{Bin}\left(N, p_{01}+p_{10}\right)+2 \operatorname{Bin}\left(N, p_{11}\right)$, which is independent of the inventories $\left(z_{1}, z_{2}\right)$.

\subsection{Optimal Replenishments}

In the replenishment problem, the amount of inventory $\left(z_{1}, z_{2}\right)$ to start a replenishment cycle is determined when the inventory level $\left(y_{1}, y_{2}\right)$ at the end of the previous cycle is given. After ordering $z_{1}-y_{1}$ and $z_{2}-y_{2}$ at a cost of $c$ per item at the beginning of a cycle, the demand is met over a replenishment cycle by incurring the cost $V_{N}\left(z_{1}, z_{2}\right)$. The cost over infinitely many replenishment cycles can be calculated by a dynamic program.

$$
\begin{aligned}
& W\left(y_{1}, y_{2}\right)=\min _{z_{1} \geq y_{1}, z_{2} \geq y_{2}}\left\{c\left(z_{1}+z_{2}-y_{1}-y_{2}\right)+V_{N}\left(z_{1}, z_{2}\right)\right. \\
& +\alpha E\left[W\left(z_{1}-\xi_{1}\left(z_{1}, z_{2}\right), z_{2}-\xi_{2}\left(z_{1}, z_{2}\right)\right]\right\},
\end{aligned}
$$

where $\alpha$ is the discount factor over a replenishment cycle. From (7), it is clear that each replenishment problem requires the solution of the transshipment problem to get $V_{N}\left(z_{1}, z_{2}\right)$ in equations (2)-(6). Thus, the transshipment problem is nested within the replenishment problem.

Although (7) appears to be a standard dynamic program arising in various inventory control contexts, dependence of $\xi_{1}$ and $\xi_{2}$ on $\left(z_{1}, z_{2}\right)$ makes it challenging to deal with. Consequently, an order-up-to policy may not be optimal for replenishment. To keep our focus on transshipment policies, we choose to order up to $\left(Z_{1}, Z_{2}\right)$ at the beginning of cycle $t$, regardless of the inventory $\left(y_{1}^{t}, y_{2}^{t}\right)$ at the end of the previous cycle. Then the optimal orderup-to values are found from

$$
\begin{aligned}
& \min _{Z_{1}, Z_{2}} E \sum_{t=1}^{\infty} \alpha^{t-1}\left\{c\left(Z_{1}+Z_{2}-y_{1}^{t}-y_{2}^{t}\right)+V_{N}\left(Z_{1}, Z_{2}\right)\right\} \\
& =\min _{Z_{1}, Z_{2}}\left\{c\left(Z_{1}+Z_{2}-y_{1}^{1}-y_{2}^{1}\right)+V_{N}\left(Z_{1}, Z_{2}\right)\right. \\
& \left.+\frac{\alpha}{1-\alpha}\left\{c E\left[\xi_{1}\left(Z_{1}, Z_{2}\right)+\xi_{2}\left(Z_{1}, Z_{2}\right)\right]+V_{N}\left(Z_{1}, Z_{2}\right)\right\}\right\} .
\end{aligned}
$$

Since $\xi_{1}\left(Z_{1}, Z_{2}\right)+\xi_{2}\left(Z_{1}, Z_{2}\right)$ is independent of $Z_{1}$ and $Z_{2}$, it can be taken out of the minimum above. Then we have

$$
\min _{Z_{1}, Z_{2}}\left\{c\left(Z_{1}+Z_{2}-y_{1}^{1}-y_{2}^{1}\right)+\frac{1}{1-\alpha} V_{N}\left(Z_{1}, Z_{2}\right)\right\} .
$$

For ease of exposition, suppose that the initial inventory levels are such that the amount $Z_{1}+Z_{2}-y_{1}^{1}-y_{2}^{1}$ purchased at the beginning of cycle 1 is $E\left[\xi_{1}\left(Z_{1}, Z_{2}\right)+\xi_{2}\left(Z_{1}, Z_{2}\right)\right]$. Consequently, $Z_{1}+Z_{2}-y_{1}^{1}-y_{2}^{1}$ can also be taken out of the minimum to arrive at 


$$
\min _{Z_{1}, Z_{2} \in \mathcal{N}} V_{N}\left(Z_{1}, Z_{2}\right)
$$

which is used to obtain the optimal order-up-to values. Since (8) is dominated by the second term as $\alpha \rightarrow 1$, the difference between the order-up-to levels found from (8) and (9) vanishes when the discount factor approaches 1 . Roughly speaking, order-up-to levels that minimize the holding, backorder, and transshipment costs over a replenishment cycle also minimize the infinite horizon discounted costs. Since the replenishment cycle length is fixed, the same basestock values would minimize the average cost (cost accumulation rate per time).

The basestock levels used in replenishing inventories depend on transshipment decisions. But the reverse is not true. A transshipment decision depends only on the current inventory levels $\left(x_{1}, x_{2}\right)$ and the number of remaining periods in the cycle. Thus, transshipments do not depend on base stock levels once $\left(x_{1}, x_{2}\right)$ is given. This independence facilitates the analysis of the transshipment problem.

\subsection{Optimal Transshipments}

A transshipment may occur only when one of the facilities has inventory and the other does not. Continuing with our earlier convention, we analyze the transshipment accept/reject decisions made at facility 1 , so let $x_{1} \in \mathcal{N}$ and $x_{2} \in \mathcal{N}^{-}$. The minima in (4) represents the trade-offs of accepting/rejecting a transshipment request. Consider the event of spare part demand only at facility 2 but not at facility 1. Then facility 2 makes a part request to facility 1 . The request is accepted if $K+V_{n-1}\left(x_{1}-1, x_{2}\right)+h_{1}\left(x_{1}-1\right) \leq n \pi$ $\left.+V_{n-1}\left(x_{1}, x_{2}-1\right)\right\}+h_{1} x_{1}$

Motivated by this type of inequalities, the expression $\delta_{n}\left(x_{1}\right)=V_{n}\left(x_{1}-1, x_{2}\right)-V_{n}\left(x_{1}, x_{2}\right)$ is defined as the marginal benefit of an extra spare part at facility 1 . This benefit does not depend on $x_{2}$ for $x_{2} \leq 0$ because the backorder cost of $x_{2}$ units are already incurred until the end of the cycle; this cost is captured by the $n \pi$ term in (4).

The expression for $\delta_{n}\left(x_{1}\right)$ differs depending on whether $x_{1} \geq 3, x_{1}=2$, or $x_{1}=1$. By us ing (3), (4), ( 5 ), and $\delta_{n}\left(x_{1}\right)=V_{n}\left(x_{1}-1, x_{2}\right)-V_{n}\left(x_{1}, x_{2}\right)$, we obtain

$$
\begin{aligned}
& \quad \delta_{n}\left(x_{1}\right)=-h_{1}+\left(p_{00}+p_{01}\right) \delta_{n-1}\left(x_{1}\right) \\
& +\left(p_{10}+p_{11}\right) \delta_{n-1}\left(x_{1}-1\right) \\
& \quad+p_{01}\left[\min \left\{K+\delta_{n-1}\left(x_{1}-1\right), n \pi+h_{1}\right\}\right. \\
& \left.-\min \left\{K+\delta_{n-1}\left(x_{1}\right), n \pi+h_{1}\right\}\right], \\
& \quad+p_{11}\left[\min \left\{K+\delta_{n-1}\left(x_{1}-2\right), n \pi+h_{1}\right\}\right. \\
& \left.-\min \left\{K+\delta_{n-1}\left(x_{1}-1\right), n \pi+h_{1}\right\}\right], \\
& \quad x_{1} \geq 3, \\
& \quad \delta_{n}\left(x_{1}=2\right)=-h_{1}+\left(p_{00}+p_{01}\right) \delta_{n-1}\left(x_{1}=2\right) \\
& +\left(p_{10}+p_{11}\right) \delta_{n-1}\left(x_{1}=1\right) \\
& \quad+p_{01}\left[\min \left\{K+\delta_{n-1}\left(x_{1}=1\right), n \pi+h_{1}\right\}\right. \\
& \left.-\min \left\{K+\delta_{n-1}\left(x_{1}=2\right), n \pi+h_{1}\right\}\right], \\
& \quad+p_{11}\left[n \pi+h_{1}\right. \\
& \left.-\min \left\{K+\delta_{n-1}\left(x_{1}=1\right), n \pi+h_{1}\right\}\right], \\
& \delta_{n}\left(x_{1}=1\right)=-h_{1} \\
& +\left(p_{11}+p_{10}\right)\left(n \pi+h_{1}\right)+\left(p_{00}+p_{01}\right) \delta_{n-1}\left(x_{1}=1\right) \\
& +p_{01}\left[n \pi+h_{1}-\min \left\{K+\delta_{n-1}\left(x_{1}=1\right), n \pi+h_{1}\right\}\right] .
\end{aligned}
$$

If

$\tilde{x}_{n}^{i}:=\max \left\{x_{i} \in \mathcal{N}: \delta_{n-1}\left(x_{i}\right)>n \pi+h_{i}-K\right\}$

is the hold-back level for service facility $i$, we can prove the next theorem; see Appendix B.

Theorem 1i) It is optimal to reject (respectively, accept) the transshipment request when $x_{i} \leq \tilde{x}_{n}^{i}$ (respectively, $x_{i}>\tilde{x}_{n}^{i}$ ). The hold-back 
level is finite at facility $i$ if and only if $n \geq K /\left(\pi+h_{i}\right)$.

ii) The hold-back levels are decreasing in the remaining number $n$ of periods: $\tilde{x}_{1}^{i} \geq \tilde{x}_{2}^{i} \geq \ldots \geq \tilde{x}_{n}^{i}$.

iii) $V_{N}\left(z_{1}, z_{2}\right)$ is convex for $z_{1}, z_{2} \in \mathcal{N}$.

An interesting question is whether facility 1 holds back more or less inventory towards the end of a replenishment cycle. On one hand, facility 1 may hold back more inventory early in the cycle to meet more of the system demand later in the cycle. On the other hand, backorder costs and hence the savings that can be achieved with transshipment are higher early in the cycle. Thus, there are intuitive reasons for low and high hold-back levels early in the cycle and it deserves an analytical investigation. This question is answered formally by Theorem 1ii. According to Theorem 1ii, if there are stockouts in two consecutive periods at facility 2 , it costs less for the system to transship for the first stock-out than the second. This is because the marginal benefit of rejecting a request (value of an extra unit of inventory) increases slower from $n$ to $n+1$ remaining periods than the cost of rejecting a request $n \pi+h_{1}-K$; see Figure 1. Since the cost $V_{N}$ in (9) of the replenishment problem is convex from Theorem 1iii, the optimal order-up-to levels can be found easily from the first-order optimality conditions.

\section{COMPUTATIONAL STUDY}

To quantify the optimal transshipment benefits, we compare the heuristics of no sharing and complete sharing against our transshipment policy (partial sharing). With a no sharing policy, facilities do not share any parts. In a system using complete sharing, a transshipment request is granted every time it is needed and a unit is available at the other facility.

Figure 1. The marginal cost $n \pi+h_{1}-K$ and marginal benefit $\delta_{n-1}(x)$ of rejecting a request for $p_{10}=p_{01}=0.3, p_{11}=0.2, h_{1}=\$ 1, \pi=\$ 10, K=\$ 65$, and $x \in\{1,4,7,10\}$

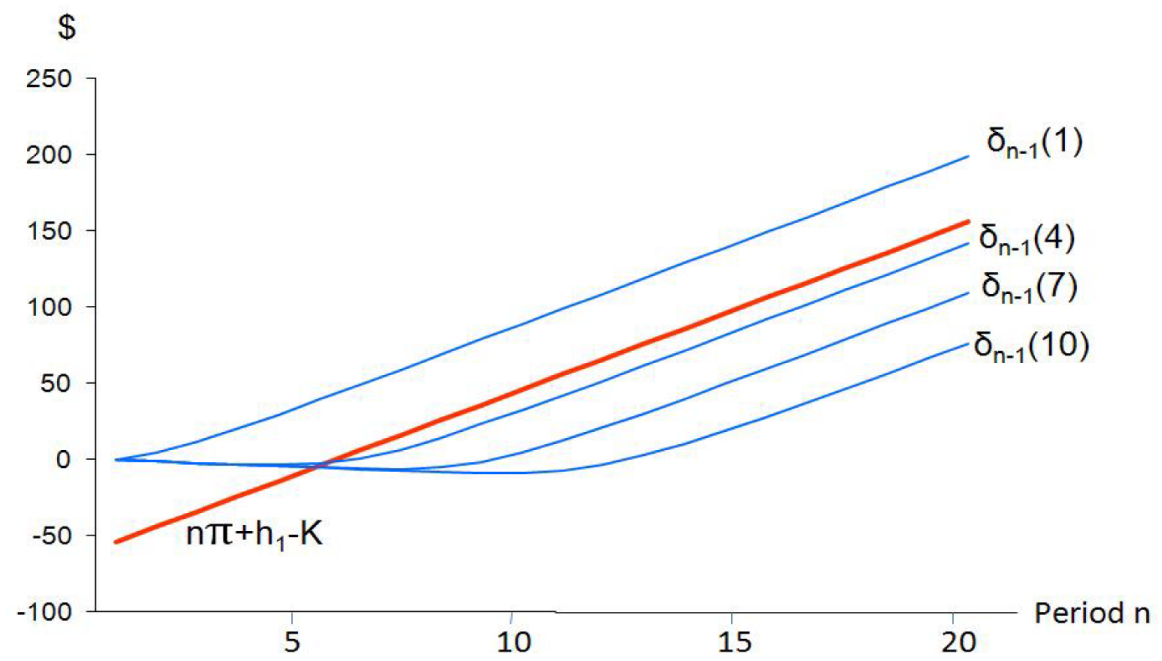


10 International Journal of Strategic Decision Sciences, 1(2), 1-27, April-June 2010

Table 1. As demand parameters change, performance of the optimal sharing policy over heuristic policies. " - " indicates that replenishment levels are the same as $Z_{1}^{*}$ and $Z_{2}^{*}$.

\begin{tabular}{|c|c|c|c|c|c|c|c|c|c|}
\hline \multirow{3}{*}{ P0 } & \multicolumn{4}{|c|}{$\begin{array}{c}\text { Base case } \\
h_{1}=h_{2}=1, \pi=10 \\
K=75\end{array}$} & $\begin{array}{l}\text { Optimal } \\
\text { Sharing }\end{array}$ & \multicolumn{2}{|c|}{$\begin{array}{c}\text { No } \\
\text { Sharing }\end{array}$} & \multicolumn{2}{|c|}{$\begin{array}{c}\text { Complete } \\
\text { Sharing }\end{array}$} \\
\hline & $p_{10}$ & $p_{01}$ & $p_{11}$ & $\rho$ & $Z_{1}^{*}, Z_{2}^{*}$ & $S^{N S}(\%)$ & $Z_{1}^{N S}, Z_{2}^{N S}$ & $S^{C S}(\%)$ & $Z_{1}^{C S}, Z_{2}^{C S}$ \\
\hline & 0.150 & 0.150 & 0.050 & 0.06 & 12,12 & 3.96 & - & 1.79 & - \\
\hline & \multicolumn{9}{|c|}{ Increasing $\rho$} \\
\hline P1 & 0.500 & 0.500 & 0.000 & -1.0 & 27,28 & 3.69 & 28,28 & 2.49 & - \\
\hline P2 & 0.375 & 0.375 & 0.125 & -0.5 & 28,28 & 2.11 & - & 2.67 & 27,28 \\
\hline P3 & 0.250 & 0.250 & 0.250 & 0.0 & 28,28 & 1.04 & - & 2.30 & - \\
\hline P4 & 0.125 & 0.125 & 0.375 & 0.5 & 28,28 & 0.26 & - & 1.74 & - \\
\hline \multirow[t]{2}{*}{ P5 } & 0.000 & 0.000 & 0.500 & 1.0 & 28,28 & 0.00 & - & 0.00 & - \\
\hline & \multicolumn{9}{|c|}{ Increasing $p_{10}$} \\
\hline P6 & 0.05 & & & 0.25 & 6,12 & 4.27 & 7,12 & 1.24 & - \\
\hline P7 & 0.25 & & & -0.05 & 17,12 & 3.90 & - & 2.06 & - \\
\hline P8 & 0.35 & & & -0.15 & 23,11 & 3.43 & 23,12 & 2.10 & - \\
\hline P9 & 0.45 & & & -0.25 & 28,11 & 3.17 & 28,12 & 2.14 & - \\
\hline & \multicolumn{9}{|c|}{ Increasing $p_{11}$} \\
\hline P10 & & & 0.15 & 0.29 & 17,17 & 1.74 & - & 1.77 & - \\
\hline P11 & & & 0.25 & 0.38 & 23,23 & 0.70 & - & 1.79 & - \\
\hline P12 & & & 0.35 & 0.40 & 28,28 & 0.39 & - & 1.88 & - \\
\hline \multirow[t]{2}{*}{ P13 } & & & 0.45 & 0.38 & 33,33 & 0.22 & - & 1.92 & - \\
\hline & \multicolumn{9}{|c|}{ Increasing $p_{10}-p_{01}$} \\
\hline P14 & 0.05 & 0.45 & & 0.00 & 6,28 & 3.32 & 7,28 & 1.61 & - \\
\hline P15 & 0.15 & 0.35 & & -0.15 & 11,23 & 3.43 & 12,23 & 2.10 & - \\
\hline P16 & 0.25 & 0.25 & & -0.19 & 17,17 & 3.90 & - & 2.30 & - \\
\hline P17 & 0.35 & 0.15 & & -0.15 & 23,11 & 3.43 & 23,12 & 2.10 & - \\
\hline P18 & 0.45 & 0.05 & & 0.00 & 28,6 & 3.32 & 28,7 & 1.61 & - \\
\hline
\end{tabular}


Table 2. As cost parameters change, performance of the optimal sharing policy over heuristic policies. " - " indicates that replenishment levels are the same as $Z_{1}^{*}$ and $Z_{2}^{*}$.

\begin{tabular}{|c|c|c|c|c|c|c|c|c|c|}
\hline \multirow{3}{*}{ P0 } & \multicolumn{4}{|c|}{$\begin{array}{c}\text { Base case } \\
p_{10}=p_{01}=0.15 \\
p_{11}=0.05\end{array}$} & $\begin{array}{l}\text { Optimal } \\
\text { Sharing }\end{array}$ & \multicolumn{2}{|c|}{$\begin{array}{l}\text { No } \\
\text { Sharing }\end{array}$} & \multicolumn{2}{|c|}{$\begin{array}{l}\text { Complete } \\
\text { Sharing }\end{array}$} \\
\hline & $h_{1}$ & $h_{2}$ & $K$ & $\pi$ & $Z_{1}^{*}, Z_{2}^{*}$ & $S^{N S}(\%)$ & $Z_{1}^{N S}, Z_{2}^{N S}$ & $S^{C S}(\%)$ & $Z_{1}^{C S}, Z_{2}^{C S}$ \\
\hline & 1 & 1 & 75 & 10 & 12,12 & 3.96 & - & 1.79 & - \\
\hline & \multicolumn{9}{|c|}{ Increasing $h_{1}, h_{2}$} \\
\hline P19 & 0.1 & 0.1 & & & 16,16 & 2.33 & - & 5.15 & - \\
\hline P20 & 0.4 & 0.4 & & & 13,14 & 3.06 & 14,14 & 3.23 & 14,14 \\
\hline $\mathrm{P} 21$ & 1.2 & 1.2 & & & 11,12 & 4.29 & 12,12 & 1.53 & 11,11 \\
\hline \multirow[t]{2}{*}{ P22 } & 1.5 & 1.5 & & & 11,11 & 4.26 & - & 1.20 & - \\
\hline & \multicolumn{9}{|c|}{ Increasing $\pi$} \\
\hline P23 & & & & 6 & 11,11 & 1.95 & - & 3.37 & - \\
\hline P24 & & & & 8 & 11,11 & 3.48 & 12,12 & 2.33 & - \\
\hline P25 & & & & 12 & 12,12 & 5.31 & - & 1.37 & - \\
\hline \multirow[t]{2}{*}{ P26 } & & & & 14 & 12,13 & 5.42 & 13,13 & 1.07 & - \\
\hline & \multicolumn{9}{|c|}{ Increasing $K$} \\
\hline P27 & & & 45 & & 11,12 & 6.13 & 12,12 & 0.42 & - \\
\hline P28 & & & 55 & & 12,12 & 5.27 & - & 0.81 & - \\
\hline P29 & & & 90 & & 12,12 & 3.11 & - & 2.64 & - \\
\hline P30 & & & 100 & & 12,12 & 2.62 & - & 3.26 & - \\
\hline
\end{tabular}

For the numerical experiments, parameters are chosen from the automobile service parts industry. The relationships among parameters are determined from our communication with dealers, related studies in the literature, and Internet sources. Most of the after-sales service is provided by dealers; almost $95 \%$ of customers served by General Motors Service Parts Operations organization are served through dealers (Wu \& Tew, 2005). Based on our personal com- munication with several automobile dealers, the replenishment cycle is chosen to be a month.

To determine the number of periods $N$ in a cycle and the demand probabilities, we consider average monthly car sales. Car parts such as battery, tires, engine block, alternator, engine belt, CV joints, and struts are normally replaced only a few times within the 10 years after the sale of a car. Indeed, some of these parts last more than the car itself. We suppose that a 
Figure 2. with $N=30$ for $p_{10}=p_{01}=0.3, p_{11}=0.15, h_{1}=\$ 0.9, \pi=\$ 9, K=\$ 60$

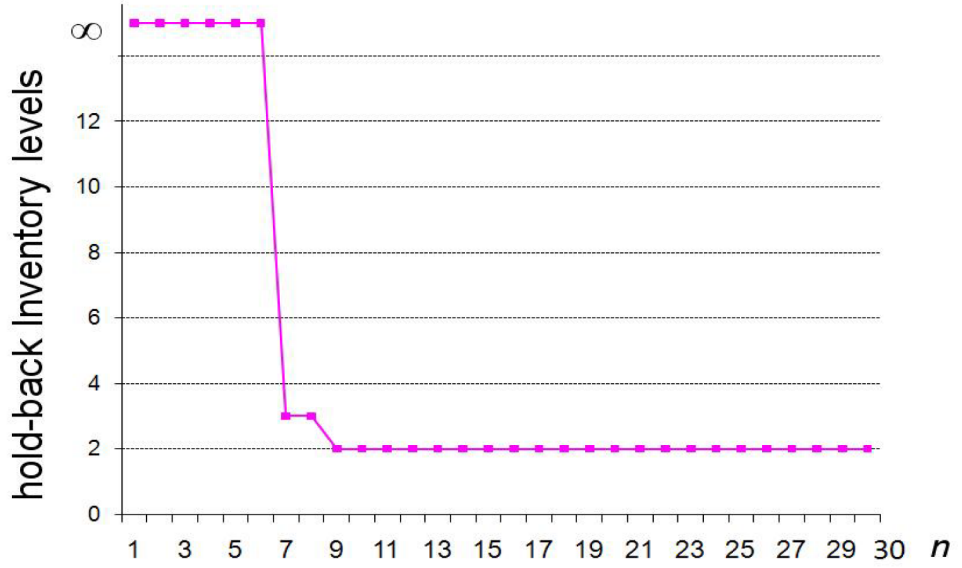

single car creates a single demand for a specific car part in our base case. We find monthly U.S. car sales publicized on manufacturer web sites and by automotive data collectors. For example, GMinsidenews.com (2007) and Toyota.com (2007a) report that Elantra and Corolla, respectively, had U.S. sales of 9,665 and 25,815 cars in March 2007. To obtain average monthly sales per dealer, we divide the sales figures by the number of dealers, which is 695 for Hyundai (Hyundai-Motor.com, 2007) and 1481 for Toyota (Toyota.com, 2007b) in the U.S. We find that an average Hyundai or Toyota dealer, respectively, sells 14 Elantras or 17 Corollas per month. The average monthly sales of 14 and 17 are covered by our parameter values in the numerical experiments. When $N=60$, each period is half of a working day

Figure 3. with $N=90$ for $p_{10}=p_{01}=0.1, p_{11}=0.05, h_{1}=\$ 0.3, \pi=\$ 3, K=\$ 60$

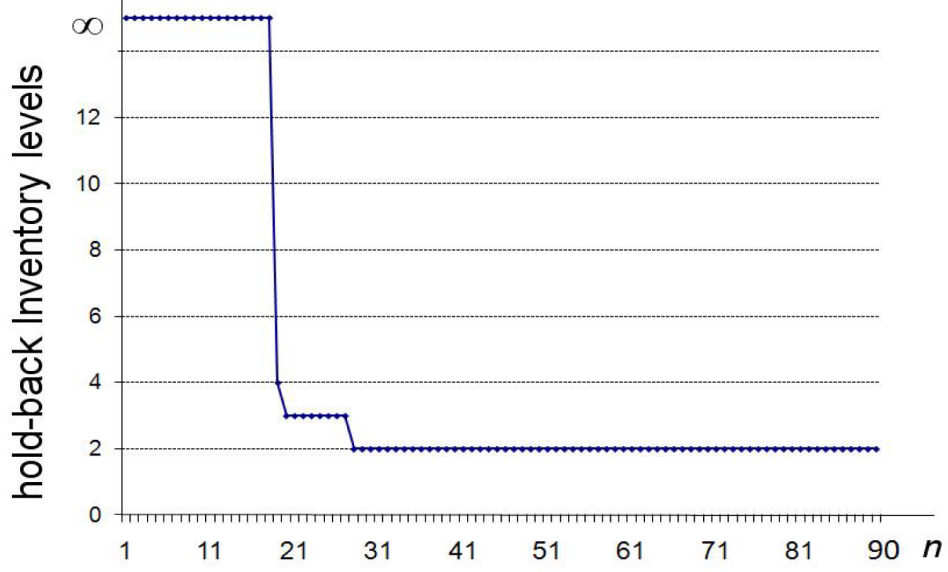


for a dealer that is open for 30 days a month. In our base case in Table 2, $p_{11}+p_{10}=p_{11}+p_{01}=0.2$, which indicates an expected monthly part demand of 12 at each dealer. For the rest of the numerical experiments, $p_{11}+p_{10}$ and $p_{11}+p_{01}$ vary between 0.1 and 0.6 , which leads to a monthly demand between 6 and 36.

When the monetary unit is scaled to have a holding cost of unity, we can specify $\pi / h$ and $K / h$ ratios. To find reasonable $\pi / h$ values, we checked some literature. For example, Cachon (2001) uses 5 and 20; SimchiLevi and Zhao (2003) use values between 4.75 and 19.75; Zhao et al. (2005) use 100; Tagaras and Vlachos (2002) use 50 and 100. In our base case, $\pi / h$ is 10 . To study problem instances with various parameter values, the ratio ranges over $(6,100)$. To choose a reasonable $K / h$ ratio, we again follow the literature. We consider the ratio $N h / K$ of the holding cost per cycle to the transshipment cost. In Tagaras and Vlachos (2002), this ratio is taken as 1.5 and 0.75 . In our base case, this ratio is $N h / K=60 * 1 / 75=0.8$ and ranges over $(0.1,1.3)$ within the experiments, which is consistent with Tagaras and Vlachos (2002).

$N$ should be chosen to be large enough to guarantee at most one demand at each facility in each period. With monthly demands about $15, N=30$ is a reasonable choice. To be on the safe side, we use $N=60$. The choice of $N$ may seem somewhat arbitrary but it does not affect the hold-back levels much, so it does not lead to an inconsistency between these levels. For example, Figure 2 and Figure 3 illustrate the hold-back levels at facility 1 for a single problem instance with two significantly different choices of $N, 30$ and 90 . When $N$ is increased by a factor of three, per period costs and demand probabilities are decreased by a factor of three; $p_{10}, p_{01}, p_{11}, h_{1}$, and $\pi$ in Figure 3 are one third of the values in Figure
2. In view of these figures, hold-back levels do not change much with $N$. For example, $\tilde{x}_{n}^{1}=3$ for about $7 \leq n \leq 8$ when $N=30$. Also $\tilde{x}_{n}^{1}=3$ for $20 \leq n \leq 27$ when $N=90$. Given that $7 \leq n \leq 8$ for $N=30$ corresponds to $21 \leq n \leq 24$ for $N=90$, we demonstrate that increasing $N$ significantly may change the hold-back pattern only slightly. In real-life implementations, the IM chooses $N$ after analyzing the historical demand data. So the IM can always ensure with a large $N$ that there is at most one demand per period.

The cost $V_{N}\left(Z_{1}, Z_{2}\right)$ with optimal $\left(Z_{1}^{*}, Z_{2}^{*}\right)$ is denoted by $V^{*}$. The cost under no sharing and complete sharing is obtained by, respectively, setting $\tilde{x}_{n}^{1}=\tilde{x}_{n}^{2}=\infty$ and $\tilde{x}_{n}^{1}=\tilde{x}_{n}^{2}=0$ for each period $n$. Let these costs be $V^{C S}$ and $V^{N S}$. Clearly $V^{C S}, V^{N S} \geq V^{*}$. We report the percent cost savings $S^{C S}$ and $S^{N S}$ obtained by o p t imal trans s i pment s: $S^{N S}=\left(V_{C S}-V^{*}\right) / V^{C S} * 100 \quad$ a n d $S^{N S}=\left(V^{N S}-V^{*}\right) / V^{N S} * 100 . Z_{1}$ and $Z_{2}$ values are also calculated optimally under the heuristic policies. Thus the $Z_{i}^{N S}$ and $Z_{i}^{C S}$ values denote the optimal replenishment values under each heuristic setting, no sharing and complete sharing, respectively.

Table 1 and Table 2 have a total of 31 problem instances, named from P0 to P30, which are used to illustrate the performance of optimal sharing via comparisons with heuristics of complete and no sharing. In each instance, the purpose is to alter some parameter values from those in the base case to see the effect of the altered parameter(s) on the benefits of optimal sharing over heuristic policies. In Table 1 and Table 2, a parameter column is blank if the value of the parameter is equal to its base case value. The base case is problem $\mathrm{P} 0$ where $N=60, h_{1}=h_{2}=\$ 1, \pi=\$ 10$, 
$K=\$ 75, \quad p_{10}=0.15, \quad p_{01}=0.15$, and $p_{11}=0.05$. Since $p_{00}=1-p_{10}-p_{01}-p_{11}$, we have $p_{00}=0.65$ in the base case.

In problems P1-P5 of Table 1, the key quantity of interest is the effect of demand correlation $\rho$ on the savings $S^{C S}$ and $S^{N S}$. To alter the demand probabilities parametrically as $\rho$ changes, set

$$
\left[\begin{array}{ll}
p_{00} & p_{01} \\
p_{10} & p_{11}
\end{array}\right]=\frac{1+\rho}{4}\left[\begin{array}{ll}
1 & 0 \\
0 & 1
\end{array}\right]+\frac{1-\rho}{4}\left[\begin{array}{ll}
0 & 1 \\
1 & 0
\end{array}\right] .
$$

It is an algebraic exercise to check that these probabilities when plugged into the correlation formula (1) yield the correlation $\rho$. To

study the effect of correlation on performance, $\rho$ is set to different values from the set $\{-1,-0.5,0,0.5,1\}$ and the corresponding demand parameters are obtained from the above equation. This equation also ensures that $p_{10}+p_{11}=0.5$ and $p_{01}+p_{11}=0.5$ throughout P1-P5. Thus, the results can only be attributed to the change in demand correlation.

The results indicate that a negative correlation between service part demands yields higher gains from optimal transshipments. This inference can be made in view of higher $S^{N S}$ and $S^{C S}$ for $\rho<0$. Most of the parameter changes in Table 1, except for those in $\rho$, cause $S^{N S}$ and $S^{C S}$ to move in opposite directions. When demands are perfectly correlated, the costs of complete sharing and no sharing heuristics coincide with the optimal cost. In this case, both facilities have leftover inventory or both stock out, either of which renders transshipments useless. This observation is supported by Herer et al. (2006), Dong and Rudi (2004), and Zhang (2005) under various transshipment and replenishment settings. On the other hand, even when demands are moder- ately correlated, P0, P2, P3, and P4 indicate considerable gains provided by the optimal transshipment policy.

In P6-P18, demand rates are altered in several different ways to model the various scenarios. The probability $p_{10}$ of demand at facility 1 is increased in P6-P9 to study facility 1 that serves a larger market size. When facility 1 is larger, the IM orders more for facility 1 . The benefit of optimal transshipments remain sizable in P6-P9. It appears that no sharing performs relatively better when facility 1 grows. When facility 1 is substantially larger than facility 2 , facility 1 cannot rely on limited inventory at facility 2 to handle stock outs. This is why the benefit of sharing drops. This drop becomes slightly stronger when the demand correlation is higher as illustrated in P10-P13. Lastly, facility 1 is made larger while facility 2 is made smaller in P14-P18 to see the effect of market size asymmetry on the performance. Optimal transshipments reduce the cost most when the facilities have symmetric market sizes. If the IM has several facilities to pair for transshipment purposes, he should pair facilities with the same/similar market sizes to obtain most benefits.

In Table 2, the effects of cost parameters on the benefits of the optimal transshipments are depicted. From P19-P26, increases in holding and backorder costs amplify the benefit of optimal transshipments. This observation reinforces the fact that our transshipments reduce both leftover inventory and stock outs. That is why the optimal transshipments perform relatively better when the leftover inventory (holding) cost or stock out (backorder) cost is high. On the other hand, when the cost of transshipping $K$ increases in P27-30, it is optimal to use transshipments more selectively. This brings the cost of optimal transshipments closer to the cost of no sharing and increases the cost savings w.r.t. the cost of complete sharing.

Results in Table 1 and Table 2 illustrate that sizable cost savings can be achieved by using optimal transshipment policies instead of a no sharing or complete sharing heuristic. 
The average cost savings are $3 \%$ and $2 \%$, respectively, over no sharing and complete sharing and the maximum cost saving exceeds $6 \%$ and $5 \%$, respectively. We depict these savings and the inferences made from Table 1 and Table 2 in Figure 4. These heuristics are drawn as balloons at the heights of $S^{N S}$ and $S^{C S}$ from the ground that represents the optimal transshipments. The balloons are pulled towards the ground by weights that represent problem parameters. For example, when $h_{1}, h_{2}$, or $\pi$ is large, the cost of complete sharing approaches the cost of optimal sharing with transshipments.

Finally, numerical experiments in Table 1 and Table 2 indicate that transshipment policy, be it optimal or heuristic, has little effect on the replenishment quantities. One may expect that the coordination among facilities through transshipments would decrease the inventory levels in the system. Increasing inventory levels with transshipments is unexpected, but it is an observation often made by previous transshipment studies such as Grahovac and Chakravarty
(2001), Zhao et al. (2005), and Zhang (2005). All of our instances have a smaller replenishment quantity in the case of optimal sharing than those in the case of no sharing. However, replenishment quantities with optimal sharing are smaller than those with complete sharing in P20, and they become larger in P21. Thus, transshipments among facilities does not necessarily reduce the inventory in the system.

\section{A SINGLE PARAMETER HEURISTIC FOR TRANSSHIPMENTS}

Our hold-back computations are based on difference equations. They are simple and fast to run. They can be implemented in a simple Excel spreadsheet to obtain the optimal holdback levels. In practice, the hold-back levels should be computed by the IM and passed to the service facilities. Most managers are familiar enough with spreadsheets to be able to compute the hold-back levels. Once hold-back levels

Figure 4. Savings $S^{N S}$ is reduced by parameters $K, p_{10}, p_{11}$, savings $S^{C S}$ is reduced by $h_{1}, h_{2}, \pi$. Both savings are reduced by demand correlation and market size asymmetry.

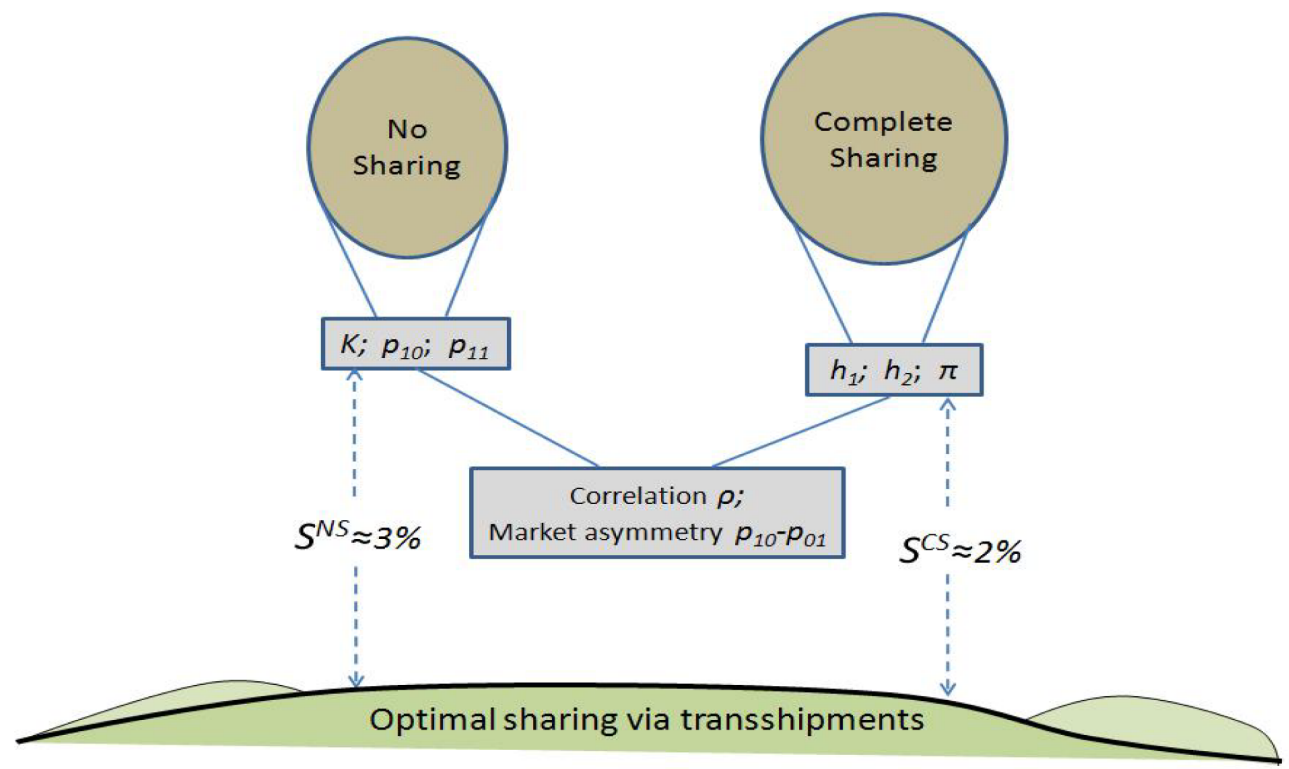


are available, all that a facility should do is to compare the current inventory level against the hold-back level during transshipment consideration. As long as the problem parameters remain the same over the replenishment cycles, the hold-back levels computed once can be used multiple times.

Despite the ease of computation and implementation of the hold-back level-based transshipments, some implementers may insist on basing the transshipment decisions on a single parameter for facility $i$ rather than $N$ parameters of hold-back levels $\left\{\tilde{x}_{n}^{i}: 1 \leq n \leq N\right\}$. The range for hold-back levels is wide, ranging from zero to infinity, so collapsing, say by averaging, such a wide range to a single number is a crude approximation. Instead of a single number, we represent the optimal transshipment policy equivalently in terms of holdback times that range from 1 to $N$.

Define the hold-back time

$$
\tilde{n}_{x}^{i}:=\max \left\{n: x \leq \tilde{x}_{n}^{i}\right\}
$$

that denotes the number of remaining periods in a cycle during which it is not optimal to grant a transshipment at retailer $i$ with inventory level $x$. If both $x$ and $n$ had been continuous, $\tilde{n}_{x}^{i}$ could have been interpreted as the inverse function of $\tilde{x}_{n}^{i}$. Then we would have $x=\tilde{x}_{\tilde{n}_{x}^{i}}^{i}$. In our discrete case, we have $\tilde{x}_{\tilde{n}_{x}^{i}+1}^{i}<x \leq \tilde{x}_{\tilde{n}_{x}^{i}}^{i}$. Since $\tilde{x}_{n}^{i}$ is decreasing in $n$ by Theorem 1ii, so is $\tilde{n}_{x}^{i}$ in $x$. For any $x$ and $n$, we can show that $\left[n \leq \tilde{n}_{x}^{i}\right]$ if and only if $\left[x \leq \tilde{x}_{n}^{i}\right]$. Therefore, rejection of a transshipment request can be equivalently based on $\left[n \leq \tilde{n}_{x}^{i}\right]$, as Archibald et al. (1997) do in a different setting than ours. Unlike Archibald et al., we have decreasing $\tilde{n}_{x}^{i}$ in $x$ (or equivalently decreasing $\tilde{x}_{n}^{i}$ in $n$ ), which implies that the inventory level of facility $i$ crosses $\tilde{x}_{n}^{i}$ only once in a replenishment cycle. Let the period when that crossing happens be $\tilde{N}^{i}$, which is a random variable as it depends on demands that drive the drop in the inventory level. The requests are rejected for $n \leq \tilde{N}^{i}$ and they are accepted for $n>\tilde{N}^{i}$.

Since $\tilde{N}^{i}$ is a demand dependent random variable, it cannot be set equal to a single number at the beginning of a replenishment cycle before demands materialize. Thus, a policy based on $\tilde{N}$ is not implementable. To gain implementability, we give up optimality. A heuristic is built with a parameter $\tilde{n}^{i}$, where requests are rejected for $n \leq \tilde{n}^{i}$. The suboptimality of the heuristic is because accept/reject decisions are specified by $\tilde{n}^{i}$, independent of the actual demand materialization during a cycle. However, demand parameters are used to calculate $\tilde{n}^{i}$, so the heuristic, despite ignoring demand materialization, captures demand expectations and correlations.

The computation of $\tilde{n}^{i}$ is not straightforward although we know that $\tilde{n}^{i} \geq K /\left(\pi+h_{i}\right)$ from Theorem 1i. For $N=60$, enumeration is used by considering $\tilde{n}^{i}=\left\lceil K /\left(\pi+h_{i}\right)\right\rceil+2$,

$\tilde{n}^{i}=\left\lceil K /\left(\pi+h_{i}\right)\right\rceil+10$, and

$\tilde{n}^{i}=\left\lceil K /\left(\pi+h_{i}\right)\right\rceil+16$ for $i \in\{1,2\}$.

To test the performance of this heuristic against our optimal transshipment policy, 1000 problem instances were generated with uniformly chosen parameter values from the following

ranges: $p_{10}, p_{01} \in(0.05,0.35), p_{11} \in(0,0.2)$, 
$h_{i} \in(0.7,1.5), \pi \in(5,12)$, and $K \in(60,100)$.

Each instance is solved to find the optimal ordering levels by using the optimal hold-back policy and by using the heuristic with $\tilde{n}^{i}$. Thus the order quantities are optimized even in the heuristic pooling policy. If $\tilde{n}$ is appended as a decision variable to the cycle cost,

$$
\text { Heuristic Cost : } \min _{z_{1}, z_{2}} V_{N}\left(z_{1}, z_{2}, \tilde{n}^{i}\right)
$$$$
\text { for a fixed value of } \tilde{n}^{i} \text {. }
$$

The increase in the cycle cost by using the heuristic policy instead of the optimal policy is calculated for each problem instance. Then average cost increases are calculated over 1000 problem instances for each value of $\tilde{n}$. The heuristic policy results in an average cost increase of $0.71 \%, 1.10 \%$, and $1.81 \%$ when the heuristic is run with, respectively, $\tilde{n}^{1}=\tilde{n}^{2}=\left\lceil K /\left(\pi+h_{i}\right)\right\rceil+2$, $\tilde{n}^{1}=\tilde{n}^{2}=\left\lceil K /\left(\pi+h_{i}\right)\right\rceil+10$, and $\tilde{n}^{1}=\tilde{n}^{2}=\left\lceil K /\left(\pi+h_{i}\right)\right\rceil+16$. Even the best value of $\tilde{n}^{1}=\tilde{n}^{2}$ results in non-negligible extra cost.

The heuristic can be improved by simultaneously optimizing over $\tilde{n}, z_{1}$, and $z_{2}$. More specifically, for a given problem instance, the cost in (13) is minimized over three variables, $\tilde{n}, z_{1}$, and $z_{2}$. Although this heuristic slightly improves the costs, it is based on enumeration that must be done in the absence of analytical structural results. Our optimal transshipment policy has a nice separation property that allows us to compute the optimal hold-back levels without knowing optimal values of $Z_{1}$ and $Z_{2}$. There is no such separation structure to exploit in the heuristic computations. From computation complexity alone, we suggest using the optimal hold-back levels (times) rather than the complicated heuristic.
The lack of separation in the heuristic is troublesome not only for computation but also for implementation. Optimal $n^{i}$ is not robust against variations in $Z_{1}$ or $Z_{2}$. In practice, because of quality problems, spoilage, theft, or damage in transport, the units received in good condition at the beginning of a cycle can be less than the optimal order quantities. In this case, a different optimal $n^{i}$ value must be computed in every cycle with the actual values of inventory available at the service facilities. This further complicates the computations/ implementation of the heuristic.

\section{CONCLUDING REMARKS}

In this paper, we propose a nested model to make optimal replenishment and transshipment decisions. The transshipment model is appropriate for service part supply chains as it considers demand dynamics, sparsity, and dependence, as well as multiple transshipments per cycle. The demand model is fairly general; its special as well as limiting cases are studied in transshipment and other settings in the literature. For this demand model, we obtain an optimal transshipment (inventory sharing) policy, which is based on hold-back levels.

The optimal sharing policy is compared to the heuristic policies of no sharing and complete sharing. The cost differences among these policies depend on parameter values and are pictured in Figure 4. A practitioner, who must implement either no sharing or complete sharing, can choose either one of these heuristics by examining cost differences under the parameter values that resemble his/her real-life setting. We also investigate heuristics based on a single parameter, a critical hold-back time. Computation of this critical time is not simple. Moreover, heuristics result in higher system costs that can be reduced by using the optimal policy. Consequently, we advocate the implementation of the hold-back level-based optimal transshipment policy. Computation of hold-back levels, say 
in a spreadsheet, is easy. Once these levels are communicated to the service part facilities, the implementation is easy as well, which does not require an IM's real time oversight. The holdback levels are robust against changes in the replenishment quantities.

\section{ACKNOWLEDGMENT}

We thank P. Schunck, BMW of Dallas, for helping us to better understand transshipments in the automobile industry. The formulation stage of this research is supported by 2008 summer research grants given to the second and third authors by the School of Management, the University of Texas at Dallas.

\section{REFERENCES}

Anupindi, R., Bassok, Y., \& Zemel, E. (2001). A General Framework for the Study of Decentralized Distribution Systems. Manufacturing \& Service Operations Management, 3(4), 349-368. doi:10.1287/ msom.3.4.349.9973

Archibald, T. W., Sassen, S. A. E., \& Thomas, L. C. (1997). An Optimal Policy for a Two Depot Inventory Problem with Stock Transfer. Management Science, 43(2), 173-183. doi:10.1287/mnsc.43.2.173

Axsäter, S. (1990). Modelling Emergency Lateral Transshipments in Inventory Systems. Management Science, 36(11), 1329-1338. doi:10.1287/ mnsc.36.11.1329

Boone, C. A., Craighead, C. W., \& Hanna, J. B. (2008). Critical Challenges of Inventory Management in Service Parts Supply: A Delphi Study. Operations Management Research, 1, 31-39. doi:10.1007/ s12063-008-0002-2

Cachon, G. P. (2001). Stock Wars: Inventory Competition in a Two-Echelon Supply Chain with Multiple Retailers. Operations Research, 49, 658-674. doi:10.1287/opre.49.5.658.10611

Çakanyıldırım, M., Royal,A. J., \& Beckett, J. (2008). Forecasting Sales for Heating, Ventilating, and Air Conditioning (HVAC) Products (Working Paper). Dallas, TX: The University of Texas at Dallas, School of Management.
Çömez, N., Stecke, K. E., \& Çakanyıldırım, M. (2009a). Multiple In-Cycle Transshipments with Positive Delivery Times (Working Paper). Dallas, TX: The University of Texas at Dallas, Richardson.

Çömez, N., Stecke, K. E., \& Çakanyıldırım, M. (2009b). Optimal Transshipments and Orders: A Tale of Two Competing and Cooperating Retailers (Working Paper). Dallas, TX: The University of Texas at Dallas, Richardson.

Complaints.com. (2009a). Retrieved April, 25, 2009, from www.complaints.com/2007/may/12/ Sears_Kenmore_dishwasher_144654.htm

Complaints.com.(2009b). Retrieved April, 25, 2009, from www.complaints.com/2007/november/30/ MATTRESS_WAREHOUSE 155511.htm

Complaints.com.(2009c). Retrieved April, 25, 2009 from www.complaints.com/2007/september/6/ Best_Buy_complaint_152271.htm

Dong, L., \& Rudi, N. (2004). Who Benefits from Transshipment? Exogenous vs. Endogenous Wholesale Prices. Management Science, 50(5), 645-657. doi: $10.1287 / \mathrm{mnsc} .1040 .0203$

Flint, P. (1995). Too Much of a Good Thing: Better Inventory Management Could Save the Industry Millions While Improving Reliability. Air Transport World, 32(9), 103-106.

Gminsidenews.com. (2007). March U.S. Car Sales By Model. Retrieved April 25, 2009, from http:// www.gminsidenews.com/forums/showthread. php?t=29676

Grahovac, J., \& Chakravarty, A. (2001). Sharing and Lateral Transshipment of Inventory in a Supply Chain with Expensive Low-Demand Items. Management Science, 47(4), 579-594. doi:10.1287/ mnsc.47.4.579.9826

Herer, Y.T., \& Rashit, A. (1999). Lateral Stock Transshipments in a Two-Location Inventory System with Fixed and Joint Replenishment Costs. Naval Research Logistics, 46, 525-547. doi:10.1002/(SICI)15206750(199908)46:5<525::AID-NAV5>3.0.CO;2-E

Herer,Y.T., Tzur,M., \& Yucesan,E.(2006). The MultiLocation Transshipment Problem. IIE Transactions, 38(3), 185-200. doi:10.1080/07408170500434539

Hyundai-Motor.com. (2007). News \& Events. Retrieved April 25, 2009, from http://www.worldwide.hyundaimotor.com/common/html/about/ news_event/press_read 2006_01.html 
Kennedy, W. J., Patterson, J. W., \& Fredendall, L. D. (2002). An Overview of Recent Literature on Spare Parts Inventories. International Journal of Production Economics, 76, 201-215. doi:10.1016/ S0925-5273(01)00174-8

Krishnan, K. S., \& Rao, V. R. K. (1965). Inventory Control in N Warehouses. Journal of Industrial Engineering, 16, 212-215.

Kukreja, A., Schmidt, C. P., \& Miller, D. M. (2001). Stocking Decisions for Low-Usage Items in a Multilocation Inventory System. Management Science, 47(10), 1371-1383. doi:10.1287/ mnsc.47.10.1371.10263

Lee, H. L., \& Tang, C. S. (1998). Variability Reduction Through Operations Reversal. Management Science, 44(2), 162-172.doi:10.1287/mnsc.44.2.162

Lee, T. C., \& Hersh, M. (1993). AModel for Dynamic Airline Seat Inventory Control with Multiple Seat Bookings. Transportation Science, 27(3), 252-265. doi: $10.1287 / \operatorname{trsc} .27 .3 .252$

Narus, J. A., \& Anderson, J. C. (1996, July-August). Rethinking Distribution: Adaptive Channels. Harvard Business Review, 112-120.

Ranaweera, C., \& Neely, A. (2003). Some Moderating Effects on the Service Quality-Customer Retention Link. International Journal of Operations \& Production Management, 23(2), 230-248. doi:10.1108/01443570310458474

Regattieri, A., Gamberi, M., Gamberini, R., \& Manzini, R. (2005). Managing Lumpy Demand for Aircraft Spare Parts. Journal of Air Transport Management, 11(6), 426-431. doi:10.1016/j.jairtraman.2005.06.003

Righter, R., \& Shanthikumar, J. G. (2001). Optimal Ordering of Operations in a Manufacturing Chain. Operations Research Letters, 29, 115-121. doi:10.1016/S0167-6377(01)00091-8

Rudi, N., Kapur, S., \& Pyke, D. F. (2001). ATwo-Location Inventory Model with Transshipment and Local Decision Making. Management Science, 47(12), 1668-1680. doi:10.1287/mnsc.47.12.1668.10235

Shahla Rostamidehbaneh, F. F. (2006). After Sales Service Necessity and Effectiveness. Unpublished master's thesis, Lulea University of Technology, Sweden.
Simchi-Levi, D., \& Zhao, Y. (2003). The Value of Information Sharing in a Two-Stage Supply Chain with Production Capacity Constraints. Naval Research Logistics, 50, 888-916. doi:10.1002/nav.10094

Sošić, G. (2006). Transshipment of Inventories Among Retailers: Myopic vs. Farsighted Stability. Management Science, 52(10), 1493-1508. doi:10.1287/mnsc. 1060.0558

Tagaras, G. (1999). Pooling in Multilocation Periodic Inventory Distribution Systems. Omega . International Journal of Management Science, 27, 39-59.

Tagaras, G., \& Cohen, M.A. (1992). Pooling in TwoLocation Inventory Systems with Non-Negligible Replenishment Lead Times. Management Science, 38(8), 1067-1083. doi:10.1287/mnsc.38.8.1067

Tagaras, G., \& Vlachos, D. (2002). Effectiveness of Stock Transshipment Under Various Demand Distributions and Nonnegligible Transshipment Times. Production and Operations Management, 11(2), 183-198.

Toyota.com. (2007a). Toyota Reports October Sales. Retrieved April 25, 2009, from http://www.toyota. com/about/news/ corporate/2007/11/01-1-sales.html

Toyota.com. (2007b). Toyota in the United States. Retrieved April 25, 2009, from http://www.toyota. com/about/our_business/at_a_glance/our_numbers/ index.html

Wu, P., \& Tew, J. D. (2005). Collaborations in the Automotive After-sales Supply Chain. In Proceedings of the Sixteenth Annual Conference of POMS, Chicago, IL.

Xu, K., Evers, P. T., \& Fu, M. C. (2003). Estimating Customer Service in a Two-Location Continuous Review Inventory Model with Emergency Transshipments. European Journal of Operational Research, 145, 569-584. doi:10.1016/S0377-2217(02)00158-3

Zandi, M. (2008, December 4). The State of the Domestic Auto Industry: Part II. Washington, DC: Testimony Before the U.S. Senate Committee on Banking, Housing, and Urban Affairs.

Zhang, J. (2005). Transshipment and Its Impact on Supply Chain Members' Performance. Management Science, 51(10), 1534-1539. doi:10.1287/ mnsc. 1050.0397 
Zhang, X. (2007). Inventory Control UnderTemporal Demand Heteroscedasticity. European Journal of Operational Research, 182, 127-144. doi:10.1016/j. ejor.2006.06.057

Zhao, H., Deshpande, V., \& Ryan, J. K. (2005). Inventory Sharing and Rationing in Decentralized Dealer Networks. Management Science, 51(4), 531-547. doi:10.1287/mnsc. 1040.0321

Zhao, H., Ryan, J. K., \& Deshpande, V. (2006). Emergency Transshipments in Decentralized Dealer Networks: When to Send and Accept Transshipment Requests. Naval Research Logistics, 53, 547-567. doi:10.1002/nav.20160
Zhao, H., Ryan, J. K., \& Deshpande, V. (2008). Optimal Dynamic Production and Inventory Transshipment Policies for a Two-Location Make-to-Stock System. Operations Research, 56(2), 400-410. doi:10.1287/opre.1070.0494

\section{ENDNOTE}

We use increasing and decreasing loosely to, respectively, mean non-decreasing and nonincreasing.

Nagihan Çömez is an assistant professor of Operations Management at the Faculty of Business Administration at Bilkent University. She holds a B.S. degree in Industrial Engineering from Bogazici University, Turkey and an M.S. degree in Supply Chain Management and a Ph.D. degree in Operations Management from the University of Texas at Dallas. She is an INFORMS member. Her research interests focus on inventory management and coordination in retailer systems, particularly on inventory sharing, inventory-pricing models, and supply chain scheduling.

Kathryn E. Stecke is the Ashbel Smith Professor of Operations Management at the University of Texas at Dallas. She received an M.S. in Applied Mathematics and an M.S. and Ph.D. in Industrial Engineering from Purdue University. She was the founding Editor-in-Chief of the International Journal of Flexible Manufacturing Systems and is Editor-in-Chief of Operations Management Education Review. She has served on both the INFORMS and POMS Board of Directors. She is an INFORMS Fellow. She has authored papers in various journals including The FMS Magazine, Material Flow, International Journal of Production Research, Journal of Marketing Channels, Operations Management Education Review, European Journal of Operational Research, IIE Transactions, Annals of Operations Research, Management Science, Production and Operations Management, Manufacturing and Services Operations Management, Operations Research, International Journal of Manufacturing Research, and others.

Metin Çakanylldırım is an associate professor at the School of Management at the University of Texas at Dallas. He received his B.S. in Industrial Engineering from Bilkent University, Turkey, his M.S. in Management Science from University of Waterloo, Canada, and his Ph.D. in Operations Research from Cornell University. He is a member of INFORMS, POMS, and IIE. His research interests include inventory and capacity management, risk management, and information security. 


\section{APPENDIX A: PARAMETER ESTIMATION}

The first parameter to estimate is the number of periods $N$ in a replenishment cycle. If $N$ is too small, there will be more than one demand occurrence in some periods at some facilities. To avoid this, first consider the demand at facility 1 and increase $N$ or equivalently shorten a period until there is at most one demand in each period at facility 1 . This gives an estimate of $N$ based on facility 1 demand. We can obtain a similar estimate from facility 2 and set $\hat{N}$ equal to the maximum of these two estimates.

$\hat{\mu}_{1}=\hat{N}\left(p_{01}+p_{11}\right)$ and $\quad \hat{\mu}_{2}=\hat{N}\left(p_{10}+p_{11}\right)$.

$\hat{\rho}=\frac{p_{00} p_{11}-p_{01} p_{10}}{\sqrt{\left(p_{10}+p_{11}\right)\left(p_{01}+p_{00}\right)\left(p_{01}+p_{11}\right)\left(p_{10}+p_{00}\right)}}$,

$\hat{\rho} \sqrt{\frac{\hat{\mu}_{1}}{\hat{N}}} \sqrt{\frac{\hat{\mu}_{2}}{\hat{N}}} \sqrt{1-\frac{\hat{\mu}_{1}}{\hat{N}}} \sqrt{1-\frac{\hat{\mu}_{2}}{\hat{N}}}=p_{00} p_{11}-p_{01} p_{10}=$

$p_{11}-p_{01} p_{11}-p_{10} p_{11}-p_{11}^{2}-p_{01} p_{10}$.

$\frac{\hat{\mu}_{1}}{\hat{N}} \frac{\hat{\mu}_{2}}{\hat{N}}=p_{01} p_{11}+p_{10} p_{11}+p_{11}^{2}+p_{01} p_{10}$

$p_{11}=\hat{\rho} \sqrt{\frac{\hat{\mu_{1}}}{\hat{N}}} \sqrt{\frac{\hat{\mu}_{2}}{\hat{N}}} \sqrt{1-\frac{\hat{\mu}_{1}}{\hat{N}}} \sqrt{1-\frac{\hat{\mu}_{2}}{\hat{N}}}+\frac{\hat{\mu}_{1}}{\hat{N}} \frac{\hat{\mu}_{2}}{\hat{N}}$.

$p_{01}=\frac{\hat{\mu}_{1}}{\hat{N}}-\hat{\rho} \sqrt{\frac{\hat{\mu}}{\hat{N}}} \sqrt{\frac{\hat{\mu}_{2}}{\hat{N}}} \sqrt{1-\frac{\hat{\mu}}{\hat{N}}} \sqrt{1-\frac{\hat{\mu}_{2}}{\hat{N}}}-\frac{\hat{\mu}_{1}}{\hat{N}} \frac{\hat{\mu}_{2}}{\hat{N}}$

$p_{10}=\frac{\hat{\mu}_{2}}{\hat{N}}-\hat{\rho} \sqrt{\frac{\hat{\mu_{1}}}{\hat{N}}} \sqrt{\frac{\hat{\mu}_{2}}{\hat{N}}} \sqrt{1-\frac{\hat{\mu}_{1}}{\hat{N}}} \sqrt{1-\frac{\hat{\mu}_{2}}{\hat{N}}}-\frac{\hat{\mu}_{1}}{\hat{N}} \frac{\hat{\mu}_{2}}{\hat{N}}$.

The last three equalities allow us to estimate the demand parameters in terms of the empirical statistics $\hat{\mu}_{1}, \hat{\mu}_{2}$, and $\hat{\rho}$. 


\section{APPENDIX B: PROOFS}

Lemma 1 is a property of the difference of two min functions. It is used for proving Theorem 1 ii.

Lemma 1 For any four real numbers $a, b, c$, and $d$,

$$
\min \{a-c, b-d\} \leq \min \{a, b\}-\min \{c, d\} \leq \max \{a-c, b-d\} .
$$

Proof.

$\min \{\mathrm{a}, \mathrm{b}\}-\min \{\mathrm{c}, \mathrm{d}\}$

$=\min \{\mathrm{a}, \mathrm{b}\}+\max \{-\mathrm{c},-\mathrm{d}\}$

$=\min \{\mathrm{a}+\max \{-\mathrm{c},-\mathrm{d}\}, \mathrm{b}+\max \{-\mathrm{c},-\mathrm{d}\}\} \geq \min \{\mathrm{a}-\mathrm{c}, \mathrm{b}-\mathrm{d}\}$,

$\min \{a, b\}-\min \{c, d\}$

$=\min \{a, b\}+\max \{-c,-d\}$

$=\max \{-c+\min \{a, b\},-d+\min \{a, b\}\} \leq \max \{a-c, b-d\}$.

Proof of Theorem 1i .To prove the first statement in i), first show that the marginal benefit is decreasing in inventory level: $\delta_{n}\left(x_{1}\right) \leq \delta_{n}\left(x_{1}-1\right)$ for $x_{1} \in \mathcal{N}$. Induction is used on the remaining number of periods $n$. Since $\delta_{0}(\cdot)=0$, we have that $\delta_{0}\left(x_{1}\right) \leq \delta_{0}\left(x_{1}-1\right)$, for $n=0$.

$\left.1\right|_{1}=\left\{1\right.$, if $n \pi+h_{1}-K<\delta_{n-1}(x) ; 0$, otherwise $\}$,

$\left.1\right|_{2}=\left\{1\right.$, if $\delta_{n-1}(x) \leq n \pi+h_{1}-K<\delta_{n-1}(x-1) ; 0$, otherwise $\}$,

$\left.1\right|_{3}=\left\{1\right.$, if $\delta_{n-1}(x-1) \leq n \pi+h_{1}-K<\delta_{n-1}(x-2) ; 0$, otherwise $\}$,

$\left.1\right|_{4}=\left\{1\right.$, if $\delta_{n-1}(x-2) \leq n \pi+h_{1}-K<\delta_{n-1}(x-3) ; 0$, otherwise $\}$,

$\left.1\right|_{5}=\left\{1\right.$, if $\delta_{n-1}(x-3) \leq n \pi+h_{1}-K ; 0$, otherwise $\}$,

For $x_{1} \geq 4$, (10) can be rewritten for inventory levels $x_{1}$ and $x_{1}-1$ by using the following indicator variables.

$$
\begin{aligned}
& \delta_{n}\left(x_{1}\right)={ }_{1}\left[-h_{1}+\left(p_{00}+p_{01}\right) \delta_{n-1}\left(x_{1}\right)+\left(p_{11}+p_{10}\right) \delta_{n-1}\left(x_{1}-1\right)\right] \\
& +\left.1\right|_{2}\left[-h_{1}+p_{00} \delta_{n-1}\left(x_{1}\right)+\left(p_{11}+p_{10}\right) \delta_{n-1}\left(x_{1}-1\right)+p_{01}\left(n \pi+h_{1}-K\right)\right] \\
& +\left.1\right|_{3}\left[-h_{1}+p_{00} \delta_{n-1}\left(x_{1}\right)+\left(p_{10}+p_{01}\right) \delta_{n-1}\left(x_{1}-1\right)+p_{11}\left(n \pi+h_{1}-K\right)\right] \\
& +\left.1\right|_{4}\left[-h_{1}+p_{00} \delta_{n-1}\left(x_{1}\right)+\left(p_{10}+p_{01}\right) \delta_{n-1}\left(x_{1}-1\right)+p_{11} \delta_{n-1}\left(x_{1}-2\right)\right]
\end{aligned}
$$




$$
\begin{aligned}
& +\left.1\right|_{5}\left[-h_{1}+p_{00} \delta_{n-1}\left(x_{1}\right)+\left(p_{10}+p_{01}\right) \delta_{n-1}\left(x_{1}-1\right)+p_{11} \delta_{n-1}\left(x_{1}-2\right)\right] . \\
& \delta_{n}\left(x_{1}-1\right)=\left.1\right|_{1}\left[-h_{1}+\left(p_{00}+p_{01}\right) \delta_{n-1}\left(x_{1}-1\right)+\left(p_{11}+p_{10}\right) \delta_{n-1}\left(x_{1}-2\right)\right] \\
& +\left.1\right|_{2}\left[-h_{1}+\left(p_{00}+p_{01}\right) \delta_{n-1}\left(x_{1}-1\right)+\left(p_{11}+p_{10}\right) \delta_{n-1}\left(x_{1}-2\right)\right] \\
& +\left.1\right|_{3}\left[-h_{1}+p_{00} \delta_{n-1}\left(x_{1}-1\right)+\left(p_{11}+p_{10}\right) \delta_{n-1}\left(x_{1}-2\right)+p_{01}\left(n \pi+h_{1}-K\right)\right] \\
& +\left.1\right|_{4}\left[-h_{1}+p_{00} \delta_{n-1}\left(x_{1}-1\right)+\left(p_{10}+p_{01}\right) \delta_{n-1}\left(x_{1}-2\right)+p_{11}\left(n \pi+h_{1}-K\right)\right] \\
& +\left.1\right|_{5}\left[-h_{1}+p_{00} \delta_{n-1}\left(x_{1}-1\right)+\left(p_{10}+p_{01}\right) \delta_{n-1}\left(x_{1}-2\right)+p_{11} \delta_{n-1}\left(x_{1}-3\right) .\right.
\end{aligned}
$$

In (15), replacing $\delta_{n-1}\left(x_{1}\right)$ and $\delta_{n-1}\left(x_{1}-1\right)$, respectively, under $\left.1\right|_{2}=1$ and $\left.1\right|_{3}=1$ with $n \pi+h_{1}-K$, the following inequality is obtained.

$$
\begin{aligned}
& \delta_{n}\left(x_{1}\right) 1 \mid \leq_{1}\left[-h_{1}+\left(p_{00}+p_{01}\right) \delta_{n-1}\left(x_{1}\right)+\left(p_{11}+p_{10}\right) \delta_{n-1}\left(x_{1}-1\right)\right] \\
& +\left.1\right|_{2}\left[-h_{1}+\left(p_{00}+p_{01}\right)\left(n \pi+h_{1}-K\right)+\left(p_{11}+p_{10}\right) \delta_{n-1}\left(x_{1}-1\right)\right] \\
& +\left.1\right|_{3}\left[-h_{1}+p_{00} \delta_{n-1}\left(x_{1}\right)+\left(p_{10}+p_{01}+p_{11}\right)\left(n \pi+h_{1}-K\right)\right] \\
& +\left.1\right|_{4}\left[-h_{1}+p_{00} \delta_{n-1}\left(x_{1}\right)+\left(p_{10}+p_{01}\right) \delta_{n-1}\left(x_{1}-1\right)+p_{11} \delta_{n-1}\left(x_{1}-2\right)\right] \\
& +\left.1\right|_{5}\left[-h_{1}+p_{00} \delta_{n-1}\left(x_{1}\right)+\left(p_{10}+p_{01}\right) \delta_{n-1}\left(x_{1}-1\right)+p_{11} \delta_{n-1}\left(x_{1}-2\right)\right] \\
& \leq \delta_{n}\left(x_{1}-1\right) .
\end{aligned}
$$

Inequality (18) follows from comparing the right hand sides of (16) and (17) while using the induction hypothesis $\delta_{n-1}\left(x_{1}\right) \leq \delta_{n-1}\left(x_{1}-1\right)$.

For $x_{1}=3$ and $x_{1}=2, \delta_{n}\left(x_{1}-1\right)$ must be based on (11) and (12), respectively, so expressions slightly differ from (15), but the proof can similarly be done by induction on $n$. This completes the proof for $\delta_{n}\left(x_{1}\right) \leq \delta_{n}\left(x_{1}-1\right)$ for $x_{1} \in \mathcal{N}$.

Recall that a transshipment request is accepted in period $n$ if $x_{1}$ satisfies $\delta_{n-1}\left(x_{1}\right) \leq n \pi+h_{1}-K$. Given that $n \pi+h_{1}-K$ is constant in period $n$ and marginal benefit is decreasing in the inventory level $x_{1}$, it can be easily induced that there exists a critical inventory level $\tilde{x}_{n}^{i}$ at facility $i$ such that for $x_{i}>\tilde{x}_{n}^{i}, \delta_{n-1}\left(x_{1}\right) \leq n \pi+h_{1}-K$, so that it is optimal to accept a transshipment request. Similarly, for $x_{i} \leq \tilde{x}_{n}^{i}, \delta_{n-1}\left(x_{1}\right)>n \pi+h_{1}-K$, so that it is optimal to reject transshipment requests.

For the proof of the second statement in i), note that the hold-back level is infinite if and only if $\lim _{x \rightarrow \infty} \delta_{n-1}(x)>n \pi+h_{1}-K$. First the existence of the limit should be established. 
Since $\delta_{n}\left(x_{1}\right)$ is decreasing, it suffices to establish a lower bound for $\delta_{n}\left(x_{1}\right)$. A crude lower bound for $\delta_{n}\left(x_{1}\right)$ comes from keeping the extra unit in inventory until the end of the cycle without attempting to use this unit to meet any demand. So $\delta_{n}\left(x_{1}\right) \geq-n h_{1}$ for any $x_{1} \in \mathcal{N}$. Hence, the limit $\delta_{n}^{\infty}:=\lim _{x_{1} \rightarrow \infty} \delta_{n}\left(x_{1}\right)$ exists.

When the limit of both sides of (10) is taken and the limits are pushed to the minima by using the continuity of minimum, we get

$$
\begin{aligned}
& \lim _{x_{1} \rightarrow \infty} \delta_{n}\left(x_{1}\right)=-h_{1}+\left(p_{00}+p_{01}\right) \delta_{n-1}^{\infty}+\left(p_{10}+p_{11}\right) \delta_{n-1}^{\infty} \\
& +p_{01}\left[\min \left\{K+\delta_{n-1}^{\infty}, n \pi+h_{1}\right\}-\min \left\{K+\delta_{n-1}^{\infty}, n \pi+h_{1}\right\}\right] \\
& +p_{11}\left[\min \left\{K+\delta_{n-1}^{\infty}, n \pi+h_{1}\right\}-\min \left\{K+\delta_{n-1}^{\infty}, n \pi+h_{1}\right\}\right] \\
& =-h_{1}+\delta_{n-1}^{\infty} .
\end{aligned}
$$

Thus we obtain $\delta_{n}^{\infty}=-h_{1}+\delta_{n-1}^{\infty}$. This in conjunction with $\delta_{0}(\cdot)=0$ implies that $\delta_{n}^{\infty}=-n h_{1}$. Given that $\lim _{x_{1} \rightarrow \infty} \delta_{n-1}(x)=-(n-1) h_{1}$ and using some algebra, $\lim _{x_{1} \rightarrow \infty} \delta_{n-1}(x)$ $\leq n \pi+h_{1}-K$ is equivalent to $n \geq \frac{K}{\pi+h_{1}}$. As a result, the hold-back level is finite if and $\begin{array}{lllllll}\mathrm{o} & \mathrm{n} & \mathrm{l} & \mathrm{y} & \mathrm{i} & \mathrm{f}\end{array}$ $n \geq K /\left(\pi+h_{1}\right)$, which completes the proof of i).

Proof of Theorem 1ii. We prove that the marginal benefit cannot increase more than $\pi$ when the number of remaining periods goes up by $1: \delta_{n}\left(x_{1}\right) \leq \delta_{n-1}\left(x_{1}\right)+\pi$ for $n, x_{1} \in \mathcal{N}$.

The statement is proved by induction first on $n$, second on $x_{1}$, and then on both. First we show that it is valid for $x_{1}=1: \delta_{n}(1) \leq \delta_{n-1}(1)+\pi$. To start the induction on $n$, the inequality is checked for $n=1$. Note that $\delta_{0}(\cdot)=0$. Then from (12), we have the following equality. $\delta_{1}(1)-\delta_{0}(1)=-h_{1}+\left(1-p_{00}\right)\left(\pi+h_{1}\right)-p_{01} \min \left\{K, \pi+h_{1}\right\} \leq\left(1-p_{00}\right) \pi-p_{00} h_{1}$ $\leq \pi$

The first inequality above is obtained by dropping the minimum term. The second inequality follows from $1-p_{00} \leq 1$.

As an induction hypothesis for $n \geq 2$, assume that $\delta_{n-1}(1)-\delta_{n-2}(1) \leq \pi$. Then 


$$
\begin{aligned}
& \delta_{n}(1)-\delta_{n-1}(1) \\
& =\left(p_{00}+p_{01}\right)\left[\delta_{n-1}(1)-\delta_{n-2}(1)\right]+\left(1-p_{00}\right) \pi \\
& +p_{01}\left[\min \left\{K+\delta_{n-2}(1),(n-1) \pi+h_{1}\right\}-\min \left\{K+\delta_{n-1}(1), n \pi+h_{1}\right\}\right] \\
& \leq\left(p_{00}+p_{01}\right)\left[\delta_{n-1}(1)-\delta_{n-2}(1)\right]+\left(1-p_{00}\right) \pi+p_{01}\left[\max \left\{\delta_{n-2}(1)-\delta_{n-1}(1),-\pi\right\}\right] \\
& =\left(1-p_{00}\right) \pi+p_{00}\left[\delta_{n-1}(1)-\delta_{n-2}(1)\right] \leq \pi .
\end{aligned}
$$

Inequality (19) follows from applying Lemma 1 with $a:=K+\delta_{n-2}(1), b:=(n-1) \pi+h_{1}$, $c:=K+\delta_{n-1}(1)$, and $d:=n \pi+h_{1}$. The equality and inequality in (20) both follow from the induction hypothesis $\delta_{n-1}(1)-\delta_{n-2}(1) \leq \pi$, which completes the proof of $\delta_{n}(1) \leq \delta_{n-1}(1)+\pi$ for every $n \in \mathcal{N}$.

For $x_{1}=2$, the inequality is first checked for $n=1$. Note that $\delta_{0}(\cdot)=0$. Then from (11), we have the following equality.

$$
\begin{aligned}
& \delta_{1}(2)-\delta_{0}(2)=-h_{1}+p_{11}\left[\pi+h_{1}-\min \left\{K, \pi+h_{1}\right\}\right] \\
& =-\left(1-p_{11}\right) h_{1}+p_{11} \pi-\min \left\{K, \pi+h_{1}\right\} \\
& \leq-\left(1-p_{11}\right) h_{1}+p_{11} \pi \leq \pi
\end{aligned}
$$

The first inequality above is obtained by dropping the minimum term. The second inequality follows from $p_{11} \leq 1$. As an induction hypothesis for $x_{1}=2$ and $n \geq 2$, assume that $\delta_{n-1}(2)-\delta_{n-2}(2) \leq \pi$. Then

$$
\begin{aligned}
& \delta_{n}(2)-\delta_{n-1}(2) \\
& =\left(p_{00}+p_{01}\right)\left[\delta_{n-1}(2)-\delta_{n-2}(2)\right]+\left(p_{10}+p_{11}\right)\left[\delta_{n-1}(1)-\delta_{n-2}(1)\right] \\
& +p_{01}\left[\min \left\{K+\delta_{n-1}(1), n \pi+h_{1}\right\}-\min \left\{K+\delta_{n-2}(1),(n-1) \pi+h_{1}\right\}\right] \\
& +p_{01}\left[\min \left\{K+\delta_{n-2}(2),(n-1) \pi+h_{1}\right\}-\min \left\{K+\delta_{n-1}(2), n \pi+h_{1}\right\}\right] \\
& +p_{11}\left[\pi+\min \left\{K+\delta_{n-2}(1),(n-1) \pi+h_{1}\right\}-\min \left\{K+\delta_{n-1}(1), n \pi+h_{1}\right\}\right] \\
& \leq\left(p_{00}+p_{01}\right)\left[\delta_{n-1}(2)-\delta_{n-2}(2)\right]+\left(p_{10}+p_{11}\right)\left[\delta_{n-1}(1)-\delta_{n-2}(1)\right] \\
& +p_{01}\left[\max \left\{\delta_{n-1}(1)-\delta_{n-2}(1), \pi\right\}+\max \left\{\delta_{n-2}(2)-\delta_{n-1}(2),-\pi\right\}\right] \\
& +p_{11} \pi+p_{11} \max \left\{\delta_{n-2}(1)-\delta_{n-1}(1),-\pi\right\}
\end{aligned}
$$




$$
=p_{00}\left[\delta_{n-1}(2)-\delta_{n-2}(2)\right]+p_{10}\left[\delta_{n-1}(1)-\delta_{n-2}(1)\right]+\left(p_{11}+p_{01}\right) \pi \leq \pi
$$

Inequality (21) follows from applying Lemma 1 . The equality and inequality in (22) both follow from the induction hypothesis $\delta_{n-1}(2)-\delta_{n-2}(2) \leq \pi$, which completes the proof of $\delta_{n}(2) \leq \delta_{n-1}(2)+\pi$ for every $n \in \mathcal{N}$.

Also $\delta_{1}\left(x_{1}\right)=-h_{1}$ for $x_{1} \geq 3$, so $\delta_{1}\left(x_{1}\right) \leq \pi$. This along with the results for $x_{1} \in\{1,2\}$ above establishes that $\delta_{1}\left(x_{1}\right) \leq \delta_{0}\left(x_{1}\right)+\pi$ for $\left[x_{1} \in \mathcal{N}\right.$ and $\left.n=1\right]$.

Up to now, it is established that $\delta_{n}\left(x_{1}\right) \leq \delta_{n-1}\left(x_{1}\right)+\pi \quad$ over $\left\{\left(x_{1}, n\right):\left[x_{1}=\{1,2\}\right.\right.$ and $\left.n \in \mathcal{N}\right]$ or $\left[x_{1} \in \mathcal{N}\right.$ and $\left.\left.n=1\right]\right\}$. These inequalities are used to start an induction on both $x_{1}$ and $n$. For $x_{1}$ and $n \geq 2$, the induction hypothesis $\delta_{n-1}\left(x_{1}\right) \leq \delta_{n-2}\left(x_{1}\right)+\pi$ is assumed. In order to ensure that the induction hypothesis holds at all $\left(x_{1}, n\right)$, consider these pairs in the following sequence. First consider all pairs of the form $\left(x_{1}, n=2\right)$ in an increasing order of $x_{1}$. Then increase $n$ by 1 and again consider the pairs in an increasing order of $x_{1}$. This sequence ensures that $\delta_{n-1}\left(x_{1}\right) \leq \delta_{n-2}\left(x_{1}\right)+\pi$ and $\delta_{n-1}\left(x_{1}-1\right) \leq \delta_{n-2}\left(x_{1}-1\right)+\pi$ while we prove that $\delta_{n}\left(x_{1}\right) \leq \delta_{n-1}\left(x_{1}\right)+\pi$.

For an arbitrary $\left(x_{1}, n\right),(10)$ is used to obtain

$$
\begin{aligned}
& \delta_{n}\left(x_{1}\right)-\delta_{n-1}\left(x_{1}\right) \\
& =\left(p_{00}+p_{01}\right)\left[\delta_{n-1}\left(x_{1}\right)-\delta_{n-2}\left(x_{1}\right)\right]+\left(p_{10}+p_{11}\right)\left[\delta_{n-1}\left(x_{1}-1\right)-\delta_{n-2}\left(x_{1}-1\right)\right] \\
& +p_{01}\left[\min \left\{K+\delta_{n-1}\left(x_{1}-1\right), n \pi+h_{1}\right\}-\min \left\{K+\delta_{n-2}\left(x_{1}-1\right),(n-1) \pi+h_{1}\right\}\right] \\
& +p_{01}\left[\min \left\{K+\delta_{n-2}\left(x_{1}\right),(n-1) \pi+h_{1}\right\}-\min \left\{K+\delta_{n-1}\left(x_{1}\right), n \pi+h_{1}\right\}\right] \\
& +p_{11}\left[\min \left\{K+\delta_{n-1}\left(x_{1}-2\right), n \pi+h_{1}\right\}-\min \left\{K+\delta_{n-2}\left(x_{1}-2\right),(n-1) \pi+h_{1}\right\}\right] \\
& +p_{11}\left[\min \left\{K+\delta_{n-2}\left(x_{1}-1\right),(n-1) \pi+h_{1}\right\}-\min \left\{K+\delta_{n-1}\left(x_{1}-1\right), n \pi+h_{1}\right\}\right] \\
& \leq\left(p_{00}+p_{01}\right)\left[\delta_{n-1}\left(x_{1}\right)-\delta_{n-2}\left(x_{1}\right)\right]+\left(p_{10}+p_{11}\right)\left[\delta_{n-1}\left(x_{1}-1\right)-\delta_{n-2}\left(x_{1}-1\right)\right] \\
& +p_{01}\left[\max \left\{\delta_{n-1}\left(x_{1}-1\right)-\delta_{n-2}\left(x_{1}-1\right), \pi\right\}+\max \left\{\delta_{n-2}\left(x_{1}\right)-\delta_{n-1}\left(x_{1}\right),-\pi\right\}\right] \\
& +p_{11}\left[\max \left\{\delta_{n-1}\left(x_{1}-2\right)-\delta_{n-2}\left(x_{1}-2\right), \pi\right\}+\max \left\{\delta_{n-2}\left(x_{1}-1\right)-\delta_{n-1}\left(x_{1}-1\right),-\pi\right\}\right] \\
& =p_{00}\left[\delta_{n-1}\left(x_{1}\right)-\delta_{n-2}\left(x_{1}\right)\right]+p_{10}\left[\delta_{n-1}\left(x_{1}-1\right)-\delta_{n-2}\left(x_{1}-1\right)\right]+\left(p_{01}+p_{11}\right) \pi \\
& \leq \pi .
\end{aligned}
$$


(23) and (24) follow from the induction hypothesis. This establishes that $\delta_{n}\left(x_{1}\right) \leq \delta_{n-1}\left(x_{1}\right)+\pi$ over $\left\{\left(x_{1}, n\right): x_{1}, n \in \mathcal{N}\right\}$.

Recall that a transshipment request is accepted in period $n$ if $x_{1}$ satisfies $\delta_{n-1}\left(x_{1}\right) \leq n \pi+h_{1}-K$. Since $n \pi+h_{1}-K$ is a linear function of the number of remaining decision periods, it increases at rate $\pi$ in $n$. It is shown above that the rate of change in marginal benefit in $n$ is at most $\pi$. Therefore, if $\delta_{n^{\prime}-1}\left(x_{1}\right)$ is below $n^{\prime} \pi+h_{1}-K$ in period $n^{\prime}$, it is always below for all $n \geq n^{\prime}$. In other words, if a request is accepted with $x_{1}$ units of inventory and with $n$ periods remaining in the cycle, it is also accepted with the same amount of inventory when $n+1$ periods remain in the cycle. That is, the hold-back level $n+1$ periods before a replenishment cannot be larger than the hold-back level $n$ periods before that replenishment: $\tilde{x}_{n+1} \leq \tilde{x}_{n}$. This completes the proof.

Proof of Theorem 1iii. First we show that $V_{n}\left(x_{1}, 0\right)$ is convex for any $n, x_{1} \in \mathcal{N}$. Since $V_{n}\left(x_{1}, 0\right)-V_{n}\left(x_{1}-1,0\right)=-\delta_{n}\left(x_{1}\right)$ and $-\delta_{n}\left(x_{1}\right)$ is increasing in $x_{1}$ by Theorem $1 \mathrm{i}$, the cost $V_{n}\left(x_{1}, 0\right)$ is convex. Similarly, we can argue that $V_{n}\left(0, x_{2}\right)$ is convex for any $n, x_{2} \in \mathcal{N}$.

The rest of the proof is by induction on $n$ while using (2). Since $V_{0}=0$, the convexity of $V_{n}$ for $n=0$ trivially holds. Now assume that $V_{n-1}\left(x_{1}, x_{2}\right)$ is convex for $x_{1}, x_{2} \in \mathcal{N}$. The term $V_{n-1}\left(x_{1}-1, x_{2}\right)$ is convex by the induction hypothesis when $x_{1} \geq 2$ and by the convexity of $V_{n-1}\left(0, x_{2}\right)$ when $x_{1}=1$. Adding linear functions of $x_{1}$ and $x_{2}$ to this, we obtain the convexity of the terms in the first square brackets in (2). The convexity of the terms inside the other square brackets can be argued similarly. Summing the convex terms inside the four square brackets, the proof is finished. 